\title{
A Guide to Survival of Momentum in UK Style Portfolios
}

\author{
Golam Sarwar \\ Cesario Mateus ${ }^{\mathrm{a}}$, \\ Natasa Todorovic ${ }^{\mathrm{b}^{*}}$ \\ ${ }^{a}$ University of Greenwich, London, UK \\ ${ }^{b}$ The Centre for Asset Management Research, \\ Cass Business School, City University, London, UK
}

In this study we estimate the survival time of momentum in six UK style portfolio returns from October 1980 to June 2014. We utilise the Kaplan-Meier estimator, a non-parametric method that measures the probability that momentum will persist beyond the present month. This probability enables us to compute the average momentum survival time for each of the six style portfolios. Discrepancies between these empirical mean survival times and those implied by theoretical models (Random Walk and ARMA $(1,1)$ ) show that there is scope for profiting from momentum trading. We illustrate this by forming long-only, short-only and long-short trading strategies that exploit positive and negative momentum and their average survival time. These trading strategies yield considerably higher Sharpe ratios than the comparative buy-and-hold strategies at a feasible level of transaction costs. This result is most pronounced for the long/short strategies. Our findings remain robust during the 2007/08 financial crisis and the aftermath, suggesting that Kaplan-Meier estimator is a powerful tool for designing a profitable momentum strategy.

JEL classification: G14, G11

Key words: Momentum survival, Style portfolios, Kaplan-Meier estimator, Trading strategies

*Corresponding author. Tel.: +44 207040 0120. E-mail addresses:g.sarwar@greenwich.ac.uk (Sarwar), c.mateus@greenwich.ac.uk (Mateus), n.todorovic@city.ac.uk (Todorovic). 
This study contributes to the equity momentum and style-timing literature by examining and exploiting the survival time of momentum in the UK style portfolio returns. The seminal paper of Jegadeesh and Titman (1993) was the first to document the outperformance of momentum trading strategies. While a significant body of research finds that trading strategies based on predictive firm characteristics (such as size, book to market ratio, leverage etc.) weaken in performance over time ${ }^{1}$, robustness of momentum investment strategy is confirmed in a number of US studies, such as Chan, Jegadeesh, \& Lakonishok (1996), Jegadeesh and Titman (2001, 2002) and Asness, Moskowitz and Pedersen (2013). Momentum profits are not restricted to the US market only; a point verified by Hon and Tonks (2003), Chelley-Steeley \& Siganos (2004), Gregory, Tharyan, \& Christidis (2013) and Liu, Strong, \& Xu (1999) who all find evidence of momentum effect in UK stock market, while Rouwenhorst (1998) documents momentum for 12 European countries.

One stream of momentum literature focuses on investigating the presence of momentum in the US style (value, growth, small cap) portfolios (see for instance Lewellen , 2002; Chen , 2003; Chen and De Bondt, 2004; Froot and Teo, 2004 and Chen, Jiang and Zhu, 2012). Similarly, Clare, Sapuric and Todorovic (2010) find that exploiting momentum in UK style portfolios proves to be a profitable investment strategy for investors following style rotation strategy. More recently, Avramov, Cheng, Schreiber and Shemer (2016) investigate momentum among 15 market anomalies in the US (total accruals, net operating assets, momentum, gross profitability, book-to-market among others). They document that while the profitability of momentum in individual anomalies fades over time, a long-short trading strategy based on a combination of winner (best performing, long position) and loser (worst performing, short position) anomalies according to lagged one-month returns generate significantly positive risk-adjusted returns and outperform the benchmark. Further, they show that momentum profits are time varying: they are stronger following the periods of high investor sentiment, a finding similar to Stambaugh, Yu and Yuan (2012).

Previous literature is in agreement that 1) momentum is present across various markets and across style portfolios and that 2) momentum profits diminish over time. However, there is a clear gap in the literature as to how long do momentum returns persist, particularly in style portfolios, i.e. portfolios where stocks are selected based on firm characteristics that resemble

${ }^{1}$ See for instance recent work by Chordia, Roll and Subrahmanyam(2011) and McLean and Pontiff (2016) 
a particular 'investment style'. In this study, we contribute to the literature by measuring the survival time of momentum on the UK equivalents of six Fama-French size/style portfolios based on popular market anomalies: size and book-to-market ratio (BTM hereafter). To investigate the survival of the momentum we construct momentum survival curves ${ }^{2}$ as in Jochum (2000) and Kos and Todorovic (2008). The study of Jochum (2000) is somewhat basic in the sense that it only identifies whether the empirical and theoretical survival curves are identical or not and explore whether the market momentum (empirical) survives longer than it should (theoretical). Kos and Todorovic (2008) extend the study of Jochum (2000) and derive trading strategies to exploit the misaligned theoretical and empirical momentum survival of US sector returns. However, neither of the two studies tests the empirical survival times in equity style portfolios, whether the empirical momentum survivals vary across business cycles or whether the estimation of momentum survival times leads to profitable momentum trading during the turbulent market conditions such as the financial crises. Our study addresses these questions and performs analysis across economic regimes and in the recent financial crisis period separately. Hence, our study fills several gaps in the literature and extends the application of survival methodology in the investment management, in particular in the area of style timing and momentum trading.

Specifically, we apply the Kaplan-Meier estimator (Kaplan and Meier, 1958; KM hereafter), a non-parametric method, which measures the likelihood that a positive/negative momentum will persist beyond the present day. In addition to estimating survival time, this model enables us to identify profit potential and feasibility of momentum trading in style portfolios. Kos and Todorovic (2008) emphasise that the KM survival methodology has a clear advantage over the Jegadeesh and Titman (1993) approach as it does not depend on zero-cost, no arbitrage portfolios which only hypothetically have zero betas and leave investors exposed to systematic risk. Further, momentum studies based on the Jegadeesh and Titman (1993) approach apply various holding periods to momentum portfolios $(1,3,6,8,12$ months being most common) to establish the persistence of momentum strategy profitability. The KM survival analysis method estimates the persistence (survival time) of the momentum in a portfolio return, without the need to test for various holding periods. In this study, we apply the KM methodology for in-sample estimation of momentum mean survival times in a number of UK style portfolios. We then provide out-of-sample tests of profitability of momentum strategies based on holding periods suggested by survival analysis.

${ }^{2}$ Kiefer(1988) provides a survey of economic survival and hazard functions 
Hence, to the best of our knowledge, this study is the first to address survival time of the momentum in the UK style portfolio returns. The study includes the period of recent financial crises that prior studies based on KM estimator do not cover. Specifically, we use monthly data in the period October 1980 to June 2014 for six UK style portfolios: Small Size \& Low BTM (SL), Small Size \& Medium BTM (SM), Small Size \& High BTM (SH), Big Size \& Low BTM (BL), Big Size \& Medium BTM (BM) and Big Size \& High BTM (BH) ${ }^{3}$. We construct empirical survival curves for momentum in each portfolio and calculate average momentum survival time (in months). We compare the empirical mean of momentum survival to the one obtained with simulated theoretical benchmarks. To establish theoretical (benchmark) momentum survival times, we deploy Monte-Carlo simulation of two commonly cited models in the description of stock returns: the Random Walk and ARMA $(1,1)$.

Any departure of empirical survival time obtained with KM estimator from the theoretical one presents an arbitrage opportunity. We exploit this opportunity for each style portfolio separately and for a combination of style portfolios. For each style portfolio, we apply longonly trading rule that buys that style portfolio once a positive momentum signal is triggered and holds it for average empirical survival time of the positive momentum. Similarly, the short-only trading rule calls for selling/short-selling of a style portfolio upon initiation of a negative momentum signal and holding that portfolio for the average negative momentum survival time. In addition, we combine the long-only and short-only trading rule for each style portfolio separately into a long/short trading rule. Finally, we form a long/short 'winnerloser' rule that implies switching across style portfolios so that: in month $\mathrm{t}$ we buy the winner style portfolio (highest positive momentum) and hold it for the average positive momentum survival time, and short-sell the loser style portfolio (lowest negative momentum) and hold the position over average negative momentum survival time. The winner/loser strategy implies that investor is engaged in exploiting momentum through style-rotation, an approach proven profitable in the UK in Clare, Sapuric and Todorovic (2010) and Levis and Liodakis (1999).

We gauge the profitability of strategies by comparing their Sharpe ratio to the Sharpe ratio of the buy-and-hold of the corresponding style portfolio. We estimate the feasibility of our trading rule by calculating breakeven transaction costs, which represent maximum costs that

\footnotetext{
${ }^{3}$ As defined in Gregory, Tharyan and Christidis (2013)
} 
investor can pay and still equalise the Sharpe ratio of the trading strategy to that of the buy and hold. Additionally, given that the strength of momentum profits varies over time (Stambaugh et al., 2012; and Avramov et al., 2016) and that UK momentum premium exhibits cyclical behaviour (Sarwar, Mateus and Todorovic, 2016), we evaluate if there are any differences in the probabilities of momentum trading across UK business cycles.

Our findings reveal that positive momentum lasts longer than the negative one; a result consistent with Jochum (2000) and Kos and Todorovic (2008). The difference in survival probabilities between empirical and theoretical models (Random Walk and ARMA $(1,1)$ process) is strongly statistically significant for momentums lasting up to eight months. Average empirical survival time of positive momentum across all portfolios is 4 months, while for negative momentum it is 3 months for small cap group of portfolios and 2 months for the large cap ones. Comparative analysis of average survival times using empirical data and benchmark model simulations shows that empirical survival time of positive momentum is underestimated by theoretical models; while it is marginally overestimated for negative momentum. This implies lesser ability of theoretical models to explain empirical price patterns on the positive momentum side, which leads us to more profitable trading based on positive momentum in our study. We show that long-only positive momentum is a feasible strategy for investors as the level of transaction costs that would make the trading unprofitable are much higher than what investors would be asked to pay in reality. Longshort strategies in our study exhibit the most consistent risk-adjusted performance across portfolios and highest incremental Sharpe ratios relative to naïve buy and hold strategies. Finally, we show that survival probabilities are not significantly different across economic regimes in most of the portfolios, implying persistence in momentum strategies. Our trading rule results corroborate this as the performance of trading strategies is not very different across economic regimes. The results also hold during the recent financial crises and its aftermath, which is in contrast to evidence provided by Andrikopoulos et al. (2013). This shows that the KM estimator has a potential to be a more powerful tool for designing a profitable momentum strategy than the approach based on pre-defined formation and holding periods (3, 6, 9, 12 months as per Jegadeesh and Titman,1993, for example), traditional in the momentum literature.

The remainder of the paper is organised as follows: Section 2 outlines the data and methodological framework; Section 3 discusses the findings and Section 4 provides conclusions to the paper and recommendations for further research. 


\subsection{Data}

This study utilizes monthly UK style portfolio data from Gregory, Tharyan and Christidis (2013) in the period October 1980 to June 2014. The data is a UK equivalent of the FamaFrench's US market data ${ }^{4}$ and is obtained from the Xfi Centre for Finance and Investment ${ }^{5}$, University of Exeter. To form the portfolios, Gregory, Tharyan and Christidis (2013) sort the sample firms on the basis of market capitalisation into 'B'-big and ' $\mathrm{S}$ '-small and on the basis of book-to-market ratio into ' $\mathrm{H}$ '-high and ' $\mathrm{L}$ '-low ${ }^{6}$ book-to-market firms. Six intersecting style portfolios are used in this study: SH; SM; SL; BH; BM; BL (where "SH" is the small size and high book-to-market portfolio, "SL" is the small size and low book-to-market portfolio, "BL" is the big size and low book-to-market portfolio and so on). The portfolios are formed at the beginning of October in year ' $t$ ', so we select October 1980 as the start of our sample period.

\subsection{Methodological framework}

\subsection{Momentum signal}

Let us provide a definition of the momentum signal used in this study. Following Jochum (2000) and Kos and Todorovic (2008), we consider momentum a technical trading rule according to which a buy (sell) signal is triggered if a positive (negative) return is realised over two consecutive periods (months). Any returns of the same sign following immediately are then added to the duration of this momentum signal and a (positive or negative) trend is formed. We consider the trend to be broken if the return changes to the opposite sign. This definition implies that positive and negative momentum trends are not necessarily alternative of each other (Jochum, 2000). For each trend, the number of periods (months) it persisted is counted (e.g. 3, 4, 5 etc.) and the direction of the trend is taken into account. The KaplanMeier estimator uses this information to calculate the survival probability of a positive (negative) trend to last, say, 3 periods.

Empirical evidence shows that profitability of momentum strategies is wiped out by high transaction costs (see for instance Carhart, 1997). To successfully link the momentum

\footnotetext{
${ }^{4}$ http://mba.tuck.dartmouth.edu/pages/faculty/ken.french/data library.html ${ }^{5} \mathrm{http} / / /$ business-school.exeter.ac.uk/research/areas/centres/xfi/research/famafrench/files/ (Accessed on 20.07.15)

${ }^{6}$ For methodology refer to Gregory et. al (2013)
} 
survival probability to a trading rule feasible for investors, the trade-off between rigidness of momentum definition (in particular, the definition of what constitutes a break of trend) and transaction cost has to be considered (Kos and Todorovic, 2008). A more rigid definition of a trend change (as in our case - where a trend is broken if the return changes the sign), will imply higher degree of transaction costs due to more frequent buy/sell decisions. By relaxing the trading rule and considering a trend change not only when the return changes sign but also when it goes over a predetermined threshold level - the transaction costs are likely to decrease. Note that the same definition of momentum signal and trend reversal/break will be applied to both actual style portfolio returns and simulated returns series, to ensure comparability.

Table 1 illustrates a sequence of momentum signals and generation of the trend. We define momentum as ' 1 ' in the table, while ' 0 ' implies that momentum is not present. For a positive trend in Table 1, we identify two momentum signals, one surviving two months and one surviving three months. Hence, the probability of three-month survival given two sequentials is $50 \%$. For the negative trend, only one momentum signal lasting one period is identified, so the probability of momentum survival for even two periods is zero.

\section{Table 1: Return Changes and Trend Construction}

The table shows an illustration of trend construction. Rows show return changes, positive and negative trend respectively over the 10 months interval (columns). Momentum signal is triggered when a positive/negative return occurs over two consecutive periods. 1 in the table denotes a (positive or negative) momentum signal and 0 implies no momentum.

\begin{tabular}{l|l|l|l|l|l|l|l|l|l|l}
\hline Month & $\mathbf{1}$ & $\mathbf{2}$ & $\mathbf{3}$ & $\mathbf{4}$ & $\mathbf{5}$ & $\mathbf{6}$ & $\mathbf{7}$ & $\mathbf{8}$ & $\mathbf{9}$ & $\mathbf{1 0}$ \\
\hline Return Changes & 0.013 & 0.009 & 0.041 & -0.011 & 0.085 & 0.074 & 0.122 & 0.010 & -0.013 & -0.001 \\
\hline Positive Trend & 0 & 1 & 1 & 0 & 0 & 1 & 1 & 1 & 0 & 0 \\
\hline Negative Trend & 0 & 0 & 0 & 0 & 0 & 0 & 0 & 0 & 0 & 1 \\
\hline
\end{tabular}

\subsection{Survival Time Estimation}

Survival analysis studies the time of survival or failure of an event (in our case - the momentum) and the probability of survival or failure of an event in a given time period. Survival analysis originates in medical research studies, but it has been successfully applied 
in economics and finance ${ }^{7}$ in the context of duration analysis for instance. In the survival study, since the data are collected over a finite period of time, it is usual that time-to-event (survival time) may not be observed for all the individual of the study sample (or population), and thus their true time-to-event is unknown. These observations are called censored observations. The analysis of such time-to-event data with censoring characteristics cannot be handled properly by the standard statistical methods, but the survival analysis. This study, similar to Jochum (2000); and Kos and Todorovic (2008), focuses on the 'survival probabilities' as this best confines the intuition behind the concept of momentum. The survival probabilities are estimated using the Kaplan-Meier estimator, as described in the next section.

\subsubsection{Kaplan-Meier Estimator}

The survival probabilities can be estimated using Kaplan-Meier method, proposed by Kaplan and Meier (1958), from the observed survival time. The KM method (also known as product limit method) is non-parametric, hence no assumptions about the distribution of survival curve have to be made.

In the KM estimator, the momentum observations of the portfolios can be ordered in accordance to the duration of momentum survival (time-to-event). The estimator also gives the probabilities of those durations. Hence, the Kaplan-Meier estimator resembles the censored generalisation of the empirical distribution function.

The proportion of the observations which have survived to the first observed survival time $t_{1}$, $\hat{S}\left(t_{1}\right)$, is given as one minus the proportion of observation which have failed by the time $t_{1}$. The latter proportion can be estimated by the number of observations that have failed (momentum trends that were broken), $d_{1}$, divided by the number of observations, which were at the risk of failure, $n_{1}$. That is, $d_{1} / n_{1}$. Similarly the proportion of momentums surviving to the second observed survival time $t_{2}, \hat{S}\left(t_{2}\right)$, is one minus the proportion of observations which failed between $t_{1}$ and $t_{2}$, multiplied by $\hat{S}\left(t_{1}\right)$; i.e. $S\left(t_{2}\right)=S\left(t_{1}\right)\left(1-\frac{d_{1}}{n_{1}}\right)$. The equation can be generalised as:

\footnotetext{
${ }^{7}$ See for instance Kiefer (1988) and Jochum (2000) among others.
} 


$$
\hat{S}\left(t_{j}\right)=\prod_{j \mid t_{t}<t}\left(1-\frac{d_{j}}{n_{j}}\right)
$$

Where, $t_{j}=$ Ordered failure time. At $t=t_{j} ; t(1) \leq t(2) \leq t(k)$

$$
d_{j}=\text { Number of failures at time } t=t_{j}
$$

$n_{j}=$ Number of observations which are alive at timet $=t_{j}$, i.e. the observations at risk of exit.

Hence, the survival function of the KM method is the product of one minus the 'failure rate' at each of the survival times. $S(t)$ is a constant between the time of events, and hence the estimated survival probably is a step function which changes only at each time when event occurs. Therefore, every step in the survival function represents the change in probability of momentum surviving beyond a given time horizon $t(j)$. This probability is conditional upon surviving, provided that the momentum is alive.

The standard error of K-M estimator at time $t$ can be calculated as:

Std. Error $=\sqrt{\operatorname{Var}(\hat{S}(t))}=\sqrt{\hat{S}^{2}(t) \sum_{t_{t}<t} \frac{d_{j}}{n_{j}\left(n_{j}-d_{j}\right)}}$

\subsection{Theoretical Survival Curves}

One of the objectives of this study is to assess whether theoretical models used in describing price behaviour can explain variations in empirical survival functions. To do so, empirical survival function for each of the six style portfolios is compared with simulated theoretical survival curves. The initial step of Monte-Carlo simulation is to formulate the model to be used for data simulation. Following Jochum, (2000) and Kos and Todorovic (2008) we apply simulation using Random Walk and Auto Regressive Moving Average (ARMA(1,1)); widely used models that describe stock return behaviour. Random walk is extensively analysed in efficient market literature since (Fama, 1965), while the ARMA (1,1) model finds its support in Pagan (1996) and Fama and French (1988) among others. 
According to Random Walk literature, the market is not predictable and the price changes are independent of each other. Random walk model can be formulated as:

$p_{t}=\mu+p_{t-1}+\varepsilon_{t} ; \quad \varepsilon_{t} \sim N\left(0, \sigma_{\varepsilon}^{2}\right)$

Here, $\mu$ is the drift constant, $p_{t-1}$ is the lagged price and $\varepsilon_{t}$ is the random error term.

ARMA model uses returns rather than prices and takes into account both the lagged value of the stock return and the random error term. An ARMA $(1,1)$ is a combination Auto regressive (AR) process and Moving average (MA) process. Both AR and MA processes are based on the simple concept of random error or stochastic errors (shocks or innovations). A shock occurs between the two observations in a series and can affect the level of the series. ARMA model describes these shocks or disturbance of the time series data. AR process assumes that each value of the times series is a linear function of the lagged value(s) and a random shock. In MA process each value is determined by the average of current shocks or disturbance and lagged shocks. The order of moving average specifies the number of lagged shocks to be included in the model.

An ARMA $(1,1)$ is a combination of AR (1) and MA (1) process and can be defined as

$r_{t}=\mu+\alpha_{1} r_{t-1}+\beta_{1} \varepsilon_{t-1}+\varepsilon_{t}$

Where, $r_{t}$ is the portfolio return, $\mu$ is constant and $\varepsilon_{t}$ is the shocks or innovation of portfolio return and is a white noise, i.e. $E\left(\varepsilon_{t}\right)=0$

In the second step of Monte-Carlo simulation we estimate the parameters of both RandomWalk and ARMA $(1,1)$ process for the period October 1980 to June 2014. 10,000 simulated time series of the same length as the empirical data are produced for six style portfolios. For each of the simulated series, the survival curve is obtained.

The comparison of empirical survival curves with theoretical (simulated) ones allows us to infer whether the survival of an existing trend (positive or negative) is higher or lower than the survival gained from Random Walk with drift and ARMA $(1,1)$. In case of identical theoretical and empirical survival curves we expect that the market reflects all available information and there are less possibilities to exploit the discrepancies. However, if there are discrepancies between actual (empirical) survival time and theoretical survival time, we treat it as a sign of inefficiency as theoretical models are unable to fully capture the complexity of the empirical data. This further implies that and one could employ simple trading rules to 
generate higher returns exploiting momentum survival time in style portfolios. The trading rules applied in this study and their implementation is described in section 4.4 of the paper.

\section{$4 \quad$ Empirical Results}

\subsection{Kaplan-Meier Estimator}

The results of the step-wise calculation of Kaplan-Meier estimator for both positive and negative momentum are reported in Table 2 for Small Size and Low Book-to-Market (SL, i.e. small-growth) portfolio. To save space, the tables showing results for the remaining five portfolios $^{8}$, are available in the appendix of the working paper version of this work ${ }^{9}$. The second column of each of the aforementioned tables represents ordered failure time, i.e. the number of consecutive months the momentum has survived. We note that across all portfolios positive momentum survives longer than the negative, consistent with Jochum (2000) and Kos and Todorovic (2008). In Table 2, the maximum positive momentum sequential for SL portfolio is 11 months. The longest positive return sequential in our sample of portfolios lasts 14 months and is observed in $\mathrm{SH}$ and $\mathrm{BH}$ portfolios (reported in Tables A2 and A5 in the working paper version, respectively). This is similar to the findings of Lewellen (2002) who observes that style portfolios exhibit momentum for up to 17 months. The longest negative return sequential has been identified for 9 months in SL portfolio in Table 2. Positive and negative return continuation over horizons of 3 to 12 months is also reported in the study of Jegadeesh and Titman (1993).

\footnotetext{
${ }^{8}$ Small Size \& Medium BTM (SM), Small Size \& High BTM (SH), Big Size \& Low BTM (BL), Big Size \& Medium BTM (BM), and Big Size \& High BTM (BH)

${ }^{9}$ https://papers.ssrn.com/sol3/papers.cfm?abstract id $=2990275$
} 
This table reports the stepwise calculation of Kaplan-Meier estimator for Small Size \& Low book-to-market (SL) Portfolio. The survival function $\left(S_{t}\right)$ proportion of observations which have survived to the time $t(j)$, where $t(1) \leq t(2) \leq t(k) . n_{j}$ represents the number of observations which are still alive at time $t=t_{j} . d_{j}$ represents the number of momentum trends that have been broken at time $t=t_{j}$. The table also reports the standard error of the KM estimator. The survival function of both positive and negative momentum is reported.

\begin{tabular}{|c|c|c|c|c|c|}
\hline$j$ & $\begin{array}{l}\text { Ordered failure } \\
\text { time, } t(j)\end{array}$ & $\begin{array}{l}\text { Intact before } t \\
\left(n_{j}\right)\end{array}$ & $\begin{array}{l}\text { Ending at time } t \\
\left(d_{j}\right)\end{array}$ & $\begin{array}{l}\text { Survivor } \\
\text { function } \\
\left(S_{t}\right)\end{array}$ & $\begin{array}{l}\text { Standard Error } \\
\sqrt{\operatorname{Var}(S(t))}\end{array}$ \\
\hline \multicolumn{6}{|c|}{ Survival Function of Positive Portfolio Momentum } \\
\hline 1 & 2 & 174 & 55 & 0.6839 & 0.0352 \\
\hline 2 & 3 & 119 & 34 & 0.4885 & 0.0379 \\
\hline 3 & 4 & 85 & 25 & 0.3448 & 0.0360 \\
\hline 4 & 5 & 60 & 20 & 0.2299 & 0.0319 \\
\hline 5 & 6 & 40 & 13 & 0.1552 & 0.0274 \\
\hline 6 & 7 & 27 & 8 & 0.1092 & 0.0236 \\
\hline 7 & 8 & 19 & 6 & 0.0747 & 0.0199 \\
\hline 8 & 9 & 13 & 6 & 0.0402 & 0.0149 \\
\hline 9 & 10 & 7 & 6 & 0.0057 & 0.0057 \\
\hline 10 & 11 & 1 & 1 & 0.0000 & - \\
\hline \multicolumn{6}{|c|}{ Survival Function of Negative Portfolio Momentum } \\
\hline 1 & 2 & 71 & 36 & 0.4930 & 0.0593 \\
\hline 2 & 3 & 35 & 16 & 0.2676 & 0.0525 \\
\hline 3 & 4 & 19 & 9 & 0.1408 & 0.0413 \\
\hline 4 & 5 & 10 & 5 & 0.0704 & 0.0304 \\
\hline 5 & 6 & 5 & 2 & 0.0423 & 0.0239 \\
\hline 6 & 7 & 3 & 1 & 0.0282 & 0.0196 \\
\hline 7 & 8 & 2 & 1 & 0.0141 & 0.0140 \\
\hline 8 & 9 & 1 & 1 & 0.0000 & \\
\hline
\end{tabular}

The third column of Table 2 shows the number of 'alive' momentums before ordered failure time, $t(j)$. In the sample of 405 observations, 174 positive momentums that survive $\left(n_{j}\right)$ for two months are identified. Out of those, 55 momentums ( $d_{j}$, column 4$)$ fail at 2 months. The remaining 119 momentums continue to survive for at least three months, where 34 observations fail after three months of momentum etc. Only one momentum survived 11 months in Table 2. For negative momentum, out of 405 observations, only 71 have been identified with two months of negative momentum, 36 of which fail after two months etc.

The survival function $\left(S_{t}\right)$ can be interpreted as the probability of trend continuation until failure time $t(j)$ conditioned upon the fact that the momentum is alive in $t(j)$, where $\mathrm{t}(1) \leq \mathrm{t}(2) \leq \mathrm{t}(\mathrm{k})$. So for instance, from Table 2, the probability that the negative momentum 
survived at least 2 months is $49.30 \%$; however, the probability of it surviving at least 3 months diminishes by almost $50 \%$ to $26.76 \%$. Overall, our findings reveal that the probability of positive momentum surviving at least 2 successive months is $60 \%$ or more for all the portfolios. For negative momentum the equivalent probability is only $33 \%$ or more for all the portfolios. The standard errors of Kaplan-Meier estimators are low for all the style portfolios such that the statistical significance of survival probabilities are not at risk.

\subsection{Empirical vs. theoretical survival curves and the scope for arbitrage}

In this section, the empirical momentum survival probabilities of style portfolios are compared with those of simulated theoretical benchmark curves. If the theoretical models fully explain the empirical momentum survival process, there should be no statistically significant difference between empirical and theoretical survival probabilities. Should survival times of the empirical curves prove to be different than for the benchmark simulations, we may conclude that the Random Walk Model and the ARMA(1,1) model do not capture the full complexity of the empirical price generating process and that exploitable arbitrage opportunities exist.

Table 3 reports the survival function of theoretical survival curves (Monte-Carlo Simulation of Random Walk and ARMA $(1,1)$ process) for both positive and negative momentum for SL portfolio. Equivalent tables for the remaining five portfolios can be found Table A1 in the appendix. We use the t-test to signify the statistical difference between theoretical and empirical survival functions of corresponding ordered failure time for both positive and negative momentum. To illustrate the interpretation of Table 3 , let us use ordered failure time of two periods. According to empirical survival curve, there is $68.39 \%$ probability that positive momentum will last for two months. Compared to the theoretical curves, the probability of survival of positive momentum for two months according to the Random Walk and ARMA $(1,1)$ is considerably smaller at $50.26 \%$ and $56.94 \%$ respectively. The differences are significant $1 \%$ level. The empirical survival time of positive momentum of SL portfolio is up to 11 days, while the Random Walk model suggests it is up to 9 days; hence the zeros in the table denote zero probability of momentum surviving in the corresponding ordered failure time. 
Both Table 3 and A1 show that maximum survival time of positive momentums of simulated benchmark returns are lower than those for the empirical portfolios. The difference is by and large statistically significant across portfolios. In contrast, the negative momentums of simulated portfolios have longer survival times than empirical ones. However, this difference is not significant for portfolio SL (Table 3) and BL (Table A1, Panel C), while it is significant for shorter ordered failure times for the remaining portfolios in Table A1. Theoretical models are supposed to show us how the market is behaving and if it is fairly priced. If the survival probabilities of theoretical models are significantly different from empirical ones, there might be arbitrage opportunities to explore.

Table 3: Theoretical Survival Function for Small size and Low book-to-market (SL) portfolio

This table reports the survival function of theoretical survival curve (simulated Random Walk and ARMA $(1,1)$ process) for SL portfolio. Empirical (KM) survival curve $(\mathrm{Sj})$ is reported here for comparison purpose with theoretical survival curves. Simple t-test is performed to investigate whether the theoretical survival functions are identical to the positive or negative empirical survival functions of corresponding ordered failure time. A pvalue less than the significance level implies that the theoretical survival function is significantly different from their corresponding empirical function. Survival functions/probabilities are reported in decimal points. ${ }^{* *}, * *$ and $*$ imply the significance at $1 \%, 5 \%$ and $10 \%$ level of significance.

\begin{tabular}{|c|c|c|c|c|c|c|}
\hline \multirow{3}{*}{$\begin{array}{l}\text { Ordered } \\
\text { failure time, } \\
t(j)\end{array}$} & \multirow{2}{*}{\multicolumn{2}{|c|}{$\begin{array}{c}\text { Empirical (KM) Survival } \\
\text { Function }(S j)\end{array}$}} & \multicolumn{4}{|c|}{ Theoretical Survival Function } \\
\hline & & & \multicolumn{2}{|c|}{ Random Walk } & \multicolumn{2}{|c|}{$\operatorname{ARMA}(1,1)$} \\
\hline & $\begin{array}{l}\text { Positive } \\
\text { Momentum }\end{array}$ & $\begin{array}{l}\text { Negative } \\
\text { Momentum }\end{array}$ & $\begin{array}{l}\text { Positive } \\
\text { Momentum }\end{array}$ & $\begin{array}{l}\text { Negative } \\
\text { Momentum }\end{array}$ & $\begin{array}{l}\text { Positive } \\
\text { Momentum }\end{array}$ & $\begin{array}{l}\text { Negative } \\
\text { Momentum }\end{array}$ \\
\hline 2 & 0.6839 & 0.493 & $\begin{array}{l}0.5026^{* * *} \\
(0.0000)\end{array}$ & $\begin{array}{l}0.4959 \\
(0.9667)\end{array}$ & $\begin{array}{l}0.5694^{* * *} \\
(0.0101)\end{array}$ & $\begin{array}{l}0.5675 \\
(0.2769)\end{array}$ \\
\hline 3 & 0.4885 & 0.2676 & $\begin{array}{l}0.2461 * * * \\
(0.0000)\end{array}$ & $\begin{array}{l}0.2496 \\
(0.7687)\end{array}$ & $\begin{array}{l}0.3178 * * * \\
(0.0002)\end{array}$ & $\begin{array}{l}0.3223 \\
(0.3716)\end{array}$ \\
\hline 4 & 0.3448 & 0.1408 & $\begin{array}{l}0.1188 * * * \\
(0.0000)\end{array}$ & $\begin{array}{l}0.1266 \\
(0.7675)\end{array}$ & $\begin{array}{l}0.1748 * * * \\
(0.0000)\end{array}$ & $\begin{array}{l}0.1784 \\
(0.4374)\end{array}$ \\
\hline 5 & 0.2299 & 0.0704 & $\begin{array}{l}0.0582 * * * \\
(0.0000)\end{array}$ & $\begin{array}{l}0.0609 \\
(0.7874)\end{array}$ & $\begin{array}{l}0.0936^{* * *} \\
(0.0002)\end{array}$ & $\begin{array}{l}0.0974 \\
(0.4523)\end{array}$ \\
\hline 6 & 0.1552 & 0.0423 & $\begin{array}{l}0.0257 * * * \\
(0.0000)\end{array}$ & $\begin{array}{l}0.0296 \\
(0.6424)\end{array}$ & $\begin{array}{l}0.047 * * * \\
(0.0006)\end{array}$ & $\begin{array}{l}0.0522 \\
(0.7239)\end{array}$ \\
\hline 7 & 0.1092 & 0.0282 & $\begin{array}{l}0.0124 * * * \\
(0.0003)\end{array}$ & $\begin{array}{l}0.0118 \\
(0.4543)\end{array}$ & $\begin{array}{l}0.0235^{* *} \\
(0.01426)\end{array}$ & $\begin{array}{l}0.0261 \\
(0.9261)\end{array}$ \\
\hline 8 & 0.0747 & 0.0141 & $\begin{array}{l}0.0048 * * * \\
(0.001928)\end{array}$ & $\begin{array}{l}0.0037 \\
(0.4993)\end{array}$ & $\begin{array}{l}0.0088^{* * *} \\
(0.003)\end{array}$ & $\begin{array}{l}0.0108 \\
(0.8361)\end{array}$ \\
\hline 9 & 0.0402 & 0 & 0 & 0 & 0 & 0.0014 \\
\hline 10 & 0.0057 & & & & & 0.0007 \\
\hline 11 & 0 & & & & & 0 \\
\hline
\end{tabular}


Table 4 presents the mean survival time (restricted mean survival time) for the empirical (KM) as well as simulated (Random Walk and ARMA $(1,1)$ ) curves. The survival probability we have analysed in Tables 2 and $3, \mathrm{~S}(\mathrm{t})$ is given for the specific point in time ' $\mathrm{t}$ ' and is a summary measure. It does not, however, contain the information regarding the survival time distribution profile during the whole time interval $(0, t)$. Mean survival time or restricted mean survival time is the useful alternative which summarizes the survival process using information beyond the survival probability only at a single time $t$, representing the area under the survival curve $S(t)$ from period 0 to period $t$ (Zhao et al., 2016; Royston and Parmar, 2013). Table 4 documents that in the case of positive portfolio momentum, the mean survival time given by theoretical Random Walk or ARMA $(1,1)$ model is shorter than the empirical one; while the opposite is found for negative portfolio momentum.

Moreover, in support of findings from Table 2, the estimated empirical mean survival for the positive momentum is longer than that for the negative momentum. Positive momentum in style portfolios survives on the average around four months, while the negative average survival time is two or three months, depending on the portfolio. Kos and Todorovic (2008) point that Grinblatt, Titman and Wermers (1995) argue that fund managers tend to buy 'winning' stocks but do not sell 'losing' stocks. This tendency to buy upward moving securities reinforces positive market moves and thus creates stronger positive market momentum. These empirical findings suggest profit potentials for investors that can be exploited by adequate trading strategy. 
Table 4: Empirical and Theoretical Mean Survival Times: Six Portfolio and Full Sample Period

This table reports the mean (average) survival time for the empirical (KM) as well as simulated (RW and ARMA) curve. The estimating period is October 1980 to June 2014. Theoretical survival curves are calculated from the Monte-Carlo simulation of 10,000 time series. The mean survival time are calculated from corresponding survival curve of Kaplan-Meier estimator.

\begin{tabular}{l|l|l|l}
\hline Portfolios & $\begin{array}{l}\text { Mean Empirical } \\
(\text { KM) } \\
\text { Survival Time }\end{array}$ & $\begin{array}{l}\text { Mean RW } \\
\text { Survival Time }\end{array}$ & $\begin{array}{l}\text { Mean ARMA } \\
\text { Survival Time }\end{array}$ \\
\hline
\end{tabular}

Positive Portfolio Momentum

\begin{tabular}{l|l|l|l}
\hline Small Size \& Low BTM (SL) Portfolio & 4.132184 & 2.968687 & 3.234758 \\
\hline Small Size \& Medium BTM (SM) Portfolio & 4.172043 & 3.028482 & 3.236601 \\
\hline Small Size \& High BTM (SH) Portfolio & 4.281081 & 3.00712 & 3.232162 \\
\hline Big Size \& Low BTM (BL) Portfolio & 4.045977 & 2.989682 & 3.022612 \\
\hline Big Size \& Medium BTM (BM) Portfolio & 3.539394 & 3.022577 & 2.894845 \\
\hline Big Size \& High BTM (BH) Portfolio & 4.095808 & 2.981913 & 2.975143 \\
\hline
\end{tabular}

Negative Portfolio Momentum

\begin{tabular}{l|l|l|l}
\hline Small Size \& Low BTM (SL) Portfolio & 3.056338 & 2.978084 & 3.27121 \\
\hline Small Size \& Medium BTM (SM) Portfolio & 2.438597 & 2.985441 & 3.226335 \\
\hline Small Size \& High BTM (SH) Portfolio & 2.693548 & 2.921293 & 3.197999 \\
\hline Big Size \& Low BTM (BL) Portfolio & 2.847458 & 2.974138 & 3.07943 \\
\hline Big Size \& Medium BTM (BM) Portfolio & 2.521739 & 2.92324 & 2.791115 \\
\hline Big Size \& High BTM (BH) Portfolio & 2.52 & 2.943633 & 2.975496 \\
\hline
\end{tabular}

Overall, Table 4 suggests there is potential in exploiting momentum, particularly the positive momentum, given adequate trading strategy and feasible level of transaction costs. To assess the viability of these findings, we implement a simple trading rule as described in 4.3 and assesses the profitability of positive (long-only), negative (short-only) and combined (longshort) style portfolio momentum trading.

\subsection{Trading Strategy Design, Profitability and Transaction Costs}

We implement trading rules based on mean survival times of both positive and negative momentum for each of the six style portfolios. We estimate in-sample empirical mean survival times for positive and negative momentum for the period October 1980 to December 2000 for each of the six portfolios and report them in Table 5. The out-of-sample trading period is then 162 months, from January 2001 to June 2014.

The average empirical survival times in the in-sample period (Table 5) are almost identical to those in the overall sample (Table 4). Mean survival time of positive momentum is approximately four months for all style portfolios. Mean survival time of negative 
momentum for the small size portfolios (SL, SM and $\mathrm{SH}$ ) is approximately three months; while that falls to two months for large size portfolios (BL, BM and $\mathrm{BH}$ ).

Table 5: In-Sample Empirical Mean Survival Times for Six Style Portfolios

This table reports the empirical mean survival time of positive and negative momentum for six UK style portfolios (SL, SM, SH, BL, BM and BH) over the estimating period 1980M10 to 2000M12. These mean survival times are showing the number of months the momentum survives, and they are rounded up to the nearest whole number for the purpose of our trading strategies described in Sections 4.3.1-4.3.3 of the paper.

\begin{tabular}{l|l|l}
\hline Portfolios & $\begin{array}{l}\text { Positive Mean Empirical } \\
\text { Survival Time }\end{array}$ & $\begin{array}{l}\text { Negative Mean Empirical } \\
\text { Survival Time }\end{array}$ \\
\hline Small Size \& Low BTM (SL) Portfolio & 4.185185 & 2.888889 \\
\hline Small Size \& Medium BTM (SM) Portfolio & 4.278261 & 2.514286 \\
\hline Small Size \& High BTM (SH) Portfolio & 4.45082 & 2.6875 \\
\hline Big Size \& Low BTM (BL) Portfolio & 4.2 & 2.387097 \\
\hline Big Size \& Medium BTM (BM) Portfolio & 3.679245 & 2.384615 \\
\hline Big Size \& High BTM (BH) Portfolio & 4.486487 & 2.304348 \\
\hline
\end{tabular}

To illustrate whether exploiting empirical momentum mean survival times from Table 5 is profitable at a feasible level of transaction costs, we design trading rules easily implementable by practitioners. In the case of positive momentum, we take a long position in the relevant style portfolio if a positive momentum signal is triggered (see section 3.1 for the description of momentum signal) and hold it for the mean survival time of four months. Whereas if the negative momentum is observed, we take a short position and hold it for two months if it is in large cap portfolio and three months if in small cap portfolio. If no momentum signal is observed, we invest in the risk-free asset, proxied by the UK 3-month TBill. Based on these rules, we design four strategies: 1) Long-only based on positive momentum, 2) Short-only based on negative momentum, 3) Long positive/Short negative momentum and 4) Long in the winner style (portfolio with highest positive momentum)/Short in the loser style (lowest negative momentum portfolio). Note that the last strategy implies style rotation, i.e. that investor switches across the style portfolios over the investment horizon.

The risk-adjusted profitability of the strategies vis-à-vis their respective buy-and-hold benchmark is measured by the Sharpe ratio. As a benchmark for strategies 1) - 3) we use the buy-and-hold of the corresponding style portfolio, while for strategy 4) the buy-and-hold of the FTSE All Share Index, as a general market index in the UK. 
The importance of transaction costs for the profitability of active strategies, particularly those active strategies based on frequent trading should not be neglected. For instance, Lesmond et. al. (2004) and Agyei-Ampomah (2007) show evidence that in traditional Jegadeesh and Titman (1993) momentum trading approach transaction costs can be substantial, exceeding $50 \%$ p.a. for 3-month formation and 1-month holding period strategy. Traditional Jegadeesh and Titman (1993) momentum approach from these studies is applied to individual stocks, whereby stocks periodically enter (drop from) the winner (loser) portfolios if they meet (do not meet) eligibility criteria. Such a change in portfolio composition can be large and as frequent as once per month.

Our strategy differs from this in several ways. First, note that our study explores the length of momentum persistence and explores profitability of momentum in style portfolios (not in individual stocks). Second, the style portfolios are pre-built Fama-French small/large/value/growth portfolios. Fama-French portfolios are rebalanced once per year and our database does not provide the information on their turnover ${ }^{10}$. However, we believe that the level of turnover within Fama-French style portfolios themselves by and large does not affect our performance, but the turnover of our strategy (buying/selling style portfolios) does. Let us explain this further. In our trading strategies, our investor alternates between a relevant style portfolio and the risk-free rate over the 14-year period. We are holding (shorting) the style portfolio for the length of the mean survival time if positive (negative) momentum is observed or alternatively, we are investing in the risk-free rate. If the same momentum signal is repeated at the expiry of the mean survival time (say 4 months), we simply continue holding (shorting) the style portfolio in question. Tables 6 and 7 below show that for long positive and short negative momentum strategy we have on average less than 30 switches (between the style portfolio and the risk-free rate) over the 14 years, which implies approximately 2 switches per year. Each switch represents a change in the position from a style portfolio to the risk-free rate or vice versa. Hence, in our case, having two switches in a year implies that the first switch relates buying/selling the whole style portfolio (all its component stocks) and the second switch infers taking the opposite position, i.e. a round-trip transaction, giving us $100 \%$ turnover $^{11}$ per year (on average). Some of our strategies will incur more switches, resulting in turnover of up to $200 \%$ per year.

\footnotetext{
${ }^{10}$ Information on individual portfolio constituents and turnover is not available in the Exeter (or Kenneth French's) database

${ }^{11}$ Following Agyei-Ampomah (2007): \%Turnover = 1/2(\%Dropouts+\%New)
} 
Further, given that rebalancing of Fama-French portfolios occurs once per year, only if we are invested in the portfolio (rather than risk-free rate) at the time of rebalancing, our strategy turnover will increase by the value of turnover in the invested portfolio. If we use as a proxy for turnover in our large and small cap portfolios the yearly turnover of the MSCI UK Large cap index $(5.52 \%)^{12}$ and MSCI UK Small cap index $(6.13 \%)^{13}$, we can conclude that i) this only marginally adds to our overall strategy turnover p.a. and ii) it adds to it only when we are invested the portfolio at the time of rebalancing. Hence, we consider this additional cost has a negligible impact on our main findings.

Let us go back to the fact that our long positive and short negative momentum strategies have a turnover of around $100 \%$. The transaction costs for a UK large cap portfolio with $100 \%$ turnover are estimated to be $1.8 \%$ per year, while for a $200 \%$ turnover portfolio they are $3.1 \%{ }^{14}$ per year, according to Frontier Investment Management LLP research, and we will use those costs as a proxy for assessing the feasibility of trading in our discussion. For UK small cap portfolio transaction costs we will use as the proxy the US Small Cap portfolio costs of $2.5 \%$ per year, as in Bernstein (2000), as no equivalent UK figures were available.

To assess the feasibility of our strategies, we calculate the break-even level of transaction costs per trade for each portfolio. Those are maximum costs per trade that will equalise the Sharpe ratio of the momentum strategy to that of the buy-and-hold of the benchmark. The costs are deducted from the portfolio return in the months in which the trade occurs. Note that where we have $100 \%$ turnover per year in the strategy, the break-even cost per trade will be the same as the break-even cost per year ${ }^{15}$. In strategies where the turnover is greater, the break-even costs per trade will be converted into costs per year. The annualised breakeven transaction costs will then be compared to the threshold value of $1.8 \%$ for UK large cap portfolios and $2.5 \%$ for UK small cap portfolios as discussed above. If our breakeven transaction costs are higher than these thresholds, we consider the strategy feasible by investors. Please note that these threshold transaction costs are estimated per year, while our costs are calculated 'per trade' and in the sample period we have two or more trades every year. The mechanics, profitability and feasibility of each strategy are further discussed in the sub-sections that follow.

\footnotetext{
${ }^{12} \mathrm{https} / / / \mathrm{www} . \mathrm{msci.com} /$ documents/10199/36e2b33b-0722-476f-9dbb-e4b30629e349

${ }^{13} \mathrm{https} / / / \mathrm{www} . \mathrm{msci.com} /$ documents/10199/5ee0d6b4-bd26-4c65-a42d-8cb012fe8604

${ }^{14}$ Figures correspond to 2007 research, and given the trend of decreasing transaction costs over the years they are likely to be lower in later years in our sample: http://www.frontierim.com/files/file/download/id/592

${ }^{15}$ Cost per year $=$ turnover $\mathrm{x}$ cost per trade
} 


\subsubsection{Strategy 1) and 2): Long-only Positive Momentum and Short-only Negative Momentum in Each Portfolio}

In the long-only positive momentum strategy, we buy a style portfolio once the momentum signal is established and hold it for four months. In the short-only negative momentum, we short a style portfolio once a negative momentum is triggered and hold it for three months if small cap and two months if large cap portfolio. When no momentum is observed, both strategies assume investment in the UK 3-month T-bill. The strategies are applied to each portfolio separately.

Table 6 and Table 7 report annualised mean return, standard deviation, Sharpe ratio, the number of switches over the trading period and break-even transaction costs per switch for each of the style portfolios and for positive and negative momentum respectively. Comparative figures (where applicable) are reported for the buy-and-hold portfolios.

The results in Table 6 reveal that applying long-only positive momentum strategy results in higher returns and Sharpe ratios in all style portfolios, at a feasible level of transaction costs (compared to $1.8 \%$ threshold for large cap and $2.5 \%$ threshold for small cap portfolios as discussed in section 4.3). Exploiting positive momentum is most profitable in SH (smallvalue) portfolio, generating Sharpe ratio of 1.23 and breakeven level of transaction costs of $4.44 \%$ per trade. This means that style momentum trader can pay up to $4.44 \%$ transaction costs per trade and still generate higher Sharpe ratio than the buy-and-hold of the SH portfolio. We also show that positive momentum trading has lower standard deviation than the buy-and-hold strategy for all the portfolios.

In contrast, Table 7 shows that although strategy based on negative portfolio momentum has lower risk than the corresponding buy-and-hold, only portfolios SL and BL outperform the buy-and-hold strategy at a level of breakeven transaction costs above the threshold of $2.5 \%$ for small and $1.8 \%$ for large portfolios. This is not surprising because theoretical negative momentum survival curves are almost identical with the empirical curves for most portfolios. Hence there are less possibilities to exploit the market using the negative momentum.

In general, the results for positive momentum effects are more pronounced than negative momentum effects. The results also suggest that the survivorship model works well for both positive and negative momentum where the empirical survival curves are not identical with 
the theoretical survival curves. Hence, the survivorship model can be seen as a compelling indicator of profitable trades.

Table 6: Trading Rule Results of Positive Portfolio Momentum

For each of the six UK style portfolios (SL, SM, SH, BL, BM and BH ) the table reports annualised mean return, standard deviation and Sharpe ratio of the Long only trading strategy that alternates between investing in a style portfolio if positive momentum is observed or in the UK 1 month T-bill otherwise. The same is reported for the buy and hold strategy (long position in each portfolio). No. of switches represents the number of times we switch between the portfolio and the T-bill in the long-only strategy. Two switches are equivalent to one round trip transaction. Break-even transaction costs (TC) represent the maximum cost (in basis points, BPS) an investor can pay per switch (trade) and still perform as well as the buy and hold strategy. Trading period: January 2001 to June 2014.

\begin{tabular}{|c|c|c|c|c|c|c|}
\hline & \multicolumn{2}{|c|}{$\begin{array}{l}\text { Small Size \& Low } \\
\text { BTM (SL) Portfolio }\end{array}$} & \multicolumn{2}{|c|}{$\begin{array}{c}\text { Small Size \& Medium } \\
\text { BTM (SM) Portfolio }\end{array}$} & \multicolumn{2}{|c|}{$\begin{array}{l}\text { Small Size \& High } \\
\text { BTM (SH) Portfolio }\end{array}$} \\
\hline & $\begin{array}{l}\text { Buy } \\
\text { and Hold }\end{array}$ & $\begin{array}{l}\text { Long Only } \\
\text { Strategy }\end{array}$ & $\begin{array}{l}\text { Buy } \\
\text { and Hold }\end{array}$ & $\begin{array}{l}\text { Long Only } \\
\text { Strategy }\end{array}$ & $\begin{array}{l}\text { Buy } \\
\text { and Hold }\end{array}$ & $\begin{array}{l}\text { Long Only } \\
\text { Strategy }\end{array}$ \\
\hline Mean Return & 4.00 & 12.81 & 12.17 & 18.80 & 10.98 & 21.05 \\
\hline Std. Dev. & 19.85 & 14.01 & 17.84 & 12.45 & 20.37 & 14.12 \\
\hline Sharpe Ratio & 0.16 & 0.73 & 0.58 & 1.22 & 0.48 & 1.23 \\
\hline No. of Switches & - & 29 & - & 31 & - & 32 \\
\hline Break Even TC & - & 375.87 BPS & - & $337.78 \mathrm{BPS}$ & - & 444.65 BPS \\
\hline
\end{tabular}

\begin{tabular}{r|l|l|l|l|l|l}
\hline \multirow{2}{*}{} & \multicolumn{2}{|c|}{$\begin{array}{c}\text { Big Size \& Low } \\
\text { BTM (BL) Portfolio }\end{array}$} & \multicolumn{2}{c|}{$\begin{array}{c}\text { Big Size \& Medium } \\
\text { BTM (BM) Portfolio }\end{array}$} & \multicolumn{2}{c}{$\begin{array}{r}\text { Big Size \& High } \\
\text { BTM (BH) Portfolio }\end{array}$} \\
\cline { 2 - 7 } & $\begin{array}{l}\text { Buy } \\
\text { and Hold }\end{array}$ & $\begin{array}{l}\text { Long Only } \\
\text { Strategy }\end{array}$ & $\begin{array}{l}\text { Buy } \\
\text { And Hold }\end{array}$ & $\begin{array}{l}\text { Long Only } \\
\text { Strategy }\end{array}$ & $\begin{array}{l}\text { Buy } \\
\text { and Hold }\end{array}$ & $\begin{array}{l}\text { Long Only } \\
\text { Strategy }\end{array}$ \\
\hline & & & & & & \\
Mean Return & 5.06 & 11.79 & 6.97 & 13.26 & 6.12 & 11.94 \\
Std. Dev. & 12.17 & 7.72 & 16.46 & 10.65 & 17.34 & 12.10 \\
Sharpe Ratio & 0.23 & 1.12 & 0.32 & 0.96 & 0.27 & 0.76 \\
No. of Switches & - & 24 & - & 32 & - & 31 \\
Break Even TC & - & 372.17 BPS & - & 284.32 BPS & - & 263.65 BPS \\
\hline
\end{tabular}


For each of the six UK style portfolios (SL, SM, SH, BL, BM and BH ) the table reports annualised mean return, standard deviation and Sharpe ratio of the Short only trading strategy that alternates between investing in a style portfolio if negative momentum is observed or in the UK 1 month T-bill otherwise. The same is reported for the buy and hold strategy (long position in each portfolio). No. of switches represents the number of times we switch between the portfolio and the T-bill in the short-only strategy. Two switches are equivalent to one round trip transaction. Break-even transaction costs (TC) represent the maximum cost (in basis points, BPS) an investor can pay per switch (trade) and still perform as well as the buy and hold strategy. Trading period: January 2001 to June 2014.

\begin{tabular}{r|l|l|l|l|l|l}
\hline & \multicolumn{2}{|c|}{$\begin{array}{c}\text { Small Size \& Low } \\
\text { BTM (SL) Portfolio }\end{array}$} & \multicolumn{2}{c|}{$\begin{array}{c}\text { Small Size \& Medium } \\
\text { BTM (SM) Portfolio }\end{array}$} & \multicolumn{2}{c}{$\begin{array}{c}\text { Small Size \& High } \\
\text { BTM (SH) Portfolio }\end{array}$} \\
\cline { 2 - 7 } & $\begin{array}{l}\text { Buy } \\
\text { and Hold }\end{array}$ & $\begin{array}{l}\text { Short Only } \\
\text { Strategy }\end{array}$ & $\begin{array}{l}\text { Buy } \\
\text { and Hold }\end{array}$ & $\begin{array}{l}\text { Short Only } \\
\text { Strategy }\end{array}$ & $\begin{array}{l}\text { Buy } \\
\text { and Hold }\end{array}$ & $\begin{array}{l}\text { Short Only } \\
\text { Strategy }\end{array}$ \\
\hline & & 11.65 & 12.17 & 6.97 & 10.98 & 6.83 \\
Mean Return & 4.00 & 11.65 & 17.84 & 11.67 & 20.37 & 14.55 \\
Std. Dev. & 19.85 & 13.20 & 0.58 & 0.40 & 0.48 & 0.34 \\
Sharpe Ratio & 0.16 & 0.69 & - & 27 & - & 29 \\
No. of Switches & - & 31 & Negative & - & Negative \\
Break Even TC & - & 305.04 BPS & - & \multicolumn{2}{|c|}{} \\
\hline
\end{tabular}

\begin{tabular}{r|l|l|l|l|l|l}
\hline & \multicolumn{2}{|c|}{$\begin{array}{r}\text { Big Size \& Low } \\
\text { BTM (BL) Portfolio }\end{array}$} & \multicolumn{2}{c|}{$\begin{array}{c}\text { Big Size \& Medium } \\
\text { BTM (BM) Portfolio }\end{array}$} & \multicolumn{2}{c}{$\begin{array}{c}\text { Big Size \& High } \\
\text { BTM (BH) Portfolio }\end{array}$} \\
\cline { 2 - 7 } & $\begin{array}{l}\text { Buy } \\
\text { and Hold }\end{array}$ & $\begin{array}{l}\text { Short Only } \\
\text { Strategy }\end{array}$ & $\begin{array}{l}\text { Buy } \\
\text { and Hold }\end{array}$ & $\begin{array}{l}\text { Short Only } \\
\text { Strategy }\end{array}$ & $\begin{array}{l}\text { Buy } \\
\text { and Hold }\end{array}$ & $\begin{array}{l}\text { Short Only } \\
\text { Strategy }\end{array}$ \\
\hline & & & & & & \\
Mean Return & 5.06 & 8.98 & 6.97 & 7.56 & 6.12 & 4.94 \\
Std. Dev. & 12.17 & 7.21 & 16.46 & 8.39 & 17.34 & 9.84 \\
$\begin{aligned} \text { Sharpe Ratio } \\
\text { No. of Switches }\end{aligned}$ & 0.23 & 0.86 & 0.32 & 0.58 & 0.27 & 0.25 \\
Break Even TC & - & 23 & - & 24 & - & 35 \\
\hline
\end{tabular}

\subsubsection{Strategy 3): Long Positive/Short Negative Momentum in Each Portfolio}

This strategy is a combination of strategy 1) and 2) for each portfolio. Hence, the long (short) position in the relevant portfolios involves buying (shorting) that portfolio if a positive (negative) momentum is observed and holding it according to mean survival time. Note that we never engage in the long and short position at the same time in this strategy, but we alternate them. The performance and feasibility of the strategy are presented in Table 8 , where we report the Sharpe ratios and break-even transaction costs of the strategy and the buy-and-hold of each relevant portfolio. Our long-short strategy in each portfolio separately significantly outperforms the respective buy-and-hold benchmarks. The highest Sharpe ratio of large-growth (BL) long-short momentum strategy is 1.42 , which is more than six times that of the corresponding buy-and-hold. The level of breakeven transaction costs that equalises the Sharpe ratio of the long/short strategy to that of the buy-and-hold strategy is 
very high, at 367.09 bps. Hence, as long as one pays less than 3.67\% per each switch, they will outperform the buy-and-hold, which is verifying the feasibility of our strategy. Note that in this long/short strategy, there are 3-4 switches per year (ranging from 40-51 over 14 years across portfolios), corresponding to $150-200 \%$ portfolio turnover as two switches indicate one round-trip transaction. Assuming more extreme 200\% as annual turnover for the purpose of this discussion, our investor can afford to pay transaction costs of up to $7.34 \%(=2 \mathrm{x}$ $3.67 \%$ ) per year and still outperform the buy-and-hold strategy. As per our earlier discussion, UK large cap portfolios with $200 \%$ turnover have estimated transaction costs of $3.1 \%$ per year, implying that outperformance with our style momentum strategy is easily achievable for investors. The trading costs of small cap portfolios with $200 \%$ turnover ${ }^{16}$ will be higher than $3.1 \%$ but they are unlikely to be as high as the break-even value of $7.34 \%$.

Table 8: Long Positive/Short Negative momentum in each style portfolio

For each of the six UK style portfolios (SL, SM, SH, BL, BM and BH) the table reports annualised mean return, standard deviation and Sharpe ratio of the Long Positive/Short Negative momentum trading strategy that combines a long position if positive momentum in a portfolio is observed and a short position if negative momentum in a portfolio is observed, giving us a Long Positive/Short Negative momentum strategy. The same is reported for the buy and hold strategy (long position in each portfolio). No. of switches represents the number of times we switch between the long, the short position and the T-bill. Two switches are equivalent to one round trip transaction. Break-even transaction costs (TC) represent the maximum cost (in basis points, BPS) an investor can pay per switch (trade) and still perform as well as the buy and hold strategy. Trading period: January 2001 to June 2014.

\begin{tabular}{r|l|l|l|l|l|l}
\hline & \multicolumn{2}{|c|}{$\begin{array}{c}\text { Small Size \& Low } \\
\text { BTM (SL) Portfolio }\end{array}$} & \multicolumn{2}{c|}{$\begin{array}{c}\text { Small Size \& Medium } \\
\text { BTM (SM) Portfolio }\end{array}$} & \multicolumn{2}{c}{$\begin{array}{c}\text { Small Size \& High } \\
\text { BTM (SH) Portfolio }\end{array}$} \\
\cline { 2 - 7 } & $\begin{array}{l}\text { Buy } \\
\text { and Hold }\end{array}$ & $\begin{array}{l}\text { Long/Short } \\
\text { Strategy }\end{array}$ & $\begin{array}{l}\text { Buy } \\
\text { and Hold }\end{array}$ & $\begin{array}{l}\text { Long/Short } \\
\text { Strategy }\end{array}$ & $\begin{array}{l}\text { Buy } \\
\text { and Hold }\end{array}$ & $\begin{array}{l}\text { Long/Short } \\
\text { Strategy }\end{array}$ \\
\hline & & & & & & \\
Mean Return & 4.00 & 7.85 & 12.17 & 10.77 & 10.98 & 10.68 \\
Std. Dev. & 19.85 & 9.19 & 17.84 & 7.68 & 20.37 & 9.01 \\
Sharpe Ratio & 0.16 & 0.56 & 0.58 & 1.00 & 0.48 & 0.87 \\
No. of Switches & - & 51 & - & 40 & - & 47 \\
Break Even TC & - & 199.93 & - & 226.98 & - & 205.05 \\
\hline
\end{tabular}

\begin{tabular}{|c|c|c|c|c|c|c|}
\hline & \multicolumn{2}{|c|}{$\begin{array}{c}\text { Big Size \& Low } \\
\text { BTM (BL) Portfolio }\end{array}$} & \multicolumn{2}{|c|}{$\begin{array}{l}\text { Big Size \& Medium } \\
\text { BTM (BM) Portfolio }\end{array}$} & \multicolumn{2}{|c|}{$\begin{array}{c}\text { Big Size \& High } \\
\text { BTM (BH) Portfolio }\end{array}$} \\
\hline & $\begin{array}{l}\text { Buy } \\
\text { and Hold }\end{array}$ & $\begin{array}{l}\text { Long/Short } \\
\text { Strategy }\end{array}$ & $\begin{array}{l}\text { Buy } \\
\text { and Hold }\end{array}$ & $\begin{array}{l}\text { Long/Short } \\
\text { Strategy }\end{array}$ & $\begin{array}{l}\text { Buy } \\
\text { and Hold }\end{array}$ & $\begin{array}{l}\text { Long/Shor } \\
\text { Strategy }\end{array}$ \\
\hline Mean Return & 5.06 & 10.09 & 6.97 & 10.33 & 6.12 & 10.27 \\
\hline Std. Dev. & 12.17 & 4.93 & 16.46 & 6.25 & 17.34 & 6.68 \\
\hline Sharpe Ratio & 0.23 & 1.42 & 0.32 & 1.15 & 0.27 & 1.08 \\
\hline No. of Switches & - & 42 & - & 51 & - & 46 \\
\hline Break Even TC & - & 367.09 & - & 276.35 & - & 318.26 \\
\hline
\end{tabular}

\footnotetext{
16 The estimated size of these costs is unavailable to us
} 


\subsubsection{Strategy 4): Long Winner/Short Loser Portfolio Style Rotation Strategy}

This strategy implies buying the winner portfolio (a portfolio with highest positive momentum) in month $t$ and holding it for the mean survival time of four months, $t+3$. Once the four-month holding period expires, in month $t+4$ we identify a portfolio with the next positive momentum trigger. If more than one portfolio exhibits momentum signal in the same month, we buy the one with the highest positive momentum. We roll this on until the end of the trading period, 162 months in total. The strategy also involves simultaneously shorting a loser portfolio (a style portfolio that has the lowest negative momentum) in month $\mathrm{t}$. We hold the short position for the average negative momentum survival time (two months for large or three months for small cap portfolios). Once the short position is closed, similarly to the winner leg of the strategy, we search for the next loser style portfolio to short. In months when we are neither long nor short, we invest in the UK T-bill.

During the trading period, there is 61 'buy' and 59 'sell' signals. Over 14 years, this relates to 8.6 switches per year or 4.3 round-trips, making turnover $430 \%$ on average in this strategy. Most traded portfolio is small-growth (SL) with 34 buy/sell signals and the least traded one is SM with 4 signals. Note that we are not long (or short) in more than one portfolio at the time, but we can be short in one and long in another portfolio at the time $\mathrm{t}^{17}$. Hence, this results in the long/short style rotation strategy. Such rotation across investment styles causes inconsistent risk parameters in a portfolio; which does not comply with traditional mutual fund risk constraints. For this reason, style rotation strategies are more suitable for hedge funds than for funds pursuing more traditional, long-only, approach to investing. Style rotation applied in the context of momentum investing is found to be profitable in the UK in Clare, Sapuric and Todorovic $(2010)^{18}$ for instance.

Table 9 reports the results of the long winner/short loser style rotation strategy, including both the (long) winner and (short) loser trading results separately. We show annualised mean return, standard deviation and Sharpe ratio of the strategy and the buy-and-hold of the benchmark. As the benchmark, we chose FTSE All Share index, as a representative index for the UK market given that we switch across portfolios representing various segments of the market.

\footnotetext{
${ }^{17}$ Also, note that we do not allow the long and the short position to be in the same portfolio.

${ }^{18} \mathrm{~A}$ number of other papers documents profitability of style rotation strategies in the UK (Levis and Liodakis (1999) and Levis and Tessaromatis (2004) and the US (Kao and Shumaker (1999); Arshanapalli, Switzer and Panju (2007) among many others)
} 
This table reports the annualised Mean Return, Standard Deviation, Sharpe Ratio and break-even transaction costs (in basis points, BPS) of winner/loser momentum trading. Long Winner (Short Loser) Style rotation implies long position (short position) in the portfolio with the highest positive (lowest negative) momentum in month $t$. If the positive (negative) momentum is not observed, we invest in the UK 3-month T-Bill. Long winner/short loser strategy is the combination of the Long Winner and Short Loser style rotation. Buy-and-hold is the FTSE All Share index. Trading period: January 2001 to June 2014.

\begin{tabular}{lllll}
\hline & Mean Return (\%) & Std. Dev (\%) & Sharpe Ratio & Break-even TC \\
\hline Long Winner Style Rotation & 20.24 & 16.29 & 1.04 & 304.60 BPS \\
\hline Short Loser Style Rotation & 19.42 & 13.18 & 1.21 & 145.57 BPS \\
\hline $\begin{array}{l}\text { Long Winner/short loser Style } \\
\text { Rotation }\end{array}$ & 20.63 & 8.76 & 1.89 & 216.61 BPS \\
\hline Buy-Hold of FTSE All Share & 4.90 & 14.62 & 0.21 & \\
\hline
\end{tabular}

The long winner/short loser strategy annualised mean return in Table 9 is around four times higher $(20.63 \%)$ than that of the FTSE index $(4.90 \%)$, with nearly $6 \%$ lower standard deviation, making the strategy's annualised Sharpe ratio (1.89) nine-times that of the index $(0.21)$. Both the long and the short segment of the strategy separately generate considerably higher Sharpe ratios than the buy-and-hold. Breakeven transaction costs that equalise Sharpe ratio of the strategy to that of the FTSE All Share index are at a feasible level for investors. The break-even costs are given per trade, implying that our investor can afford to pay up to 4.3 times the figures reported in Table 9 (as the average turnover is 430\%) and still perform better than the buy-and-hold.

\subsection{Survival Across Business Cycles}

Stambaugh et. al (2012) and Avramov et al. (2016) show that the strength of momentum profits varies over time. In addition, there is evidence that momentum in the UK exhibits a degree of cyclical behaviour (see Sarwar et. al, 2016). Given this evidence, it is possible that the power of momentum and hence momentum profits in the UK style portfolios could be different across varying economic and market conditions. To assess this, we use the Log-rank and Wilcoxon tests, proposed by Peto et al. (1977), to test the null hypothesis that the momentum survival curves for style portfolios are identical across business cycles. Log Rank test is more sensitive than the Wilcoxon test to differences between groups at later points in time. Whereas, Wilcoxon test is more sensitive than the log-rank test to differences between groups that occur at early points in time. 
Table 10 reports that the null hypothesis of the equality of empirical survivor functions across business cycles. In Table 10, ' 1 ' indicates recession and ' 0 ' indicates expansion periods. To differentiate between recession and expansion periods we use OECD based Recession Indicators for the United Kingdom taken from Federal Reserve Bank of St. Louis ${ }^{19}$. In Panel A corresponding to positive momentum, only $\mathrm{SM}$ and $\mathrm{BH}$ portfolios exhibit significantly unequal survival function over economic regimes according to both Long rank and Wilcoxon test. The momentum survival curve of $\mathrm{SH}$ and $\mathrm{BM}$ portfolios are found to be significantly unequal using Log-rank test, however this is rejected by Wilcoxon test. BL and SL portfolios do not exhibit cyclical differences in momentum survival curves. Reverting the analysis to the negative momentum (Panel B), the survival curves are different across economic regimes only for BM portfolio leading us to conclude that, overall, there is no strong evidence that style portfolios have different momentum survival time under different market conditions.

Table 10: Equality of Empirical Survival Function

Log rank and Wilcoxon test is performed to check whether or not the survival functions are similar across the business cycles. The economics regimes are the OECD based Recession Indicators for the United Kingdom taken from Federal Reserve Bank of St. Louis. 1 indicates recession and ' 0 ' indicates expansion periods. ***, ** and $*$ imply the significance at $1 \%, 5 \%$ and $10 \%$ level of significance. Results are reported for each of the six portfolios for positive momentum (Panel A) and negative momentum (Panel B) separately.

\begin{tabular}{|c|c|c|c|}
\hline \multicolumn{4}{|c|}{ Panel A: Positive Portfolio Momentum } \\
\hline & $\begin{array}{l}\text { Economic } \\
\text { Regimes }\end{array}$ & $\begin{array}{l}\text { Log Rank Test } \\
\left(\chi^{2}\right)\end{array}$ & $\begin{array}{l}\text { Wilcoxon Text } \\
\left(\chi^{2}\right)\end{array}$ \\
\hline \multirow{2}{*}{ SL } & 0 & \multirow{2}{*}{$\begin{array}{l}0.41 \\
(0.5223)\end{array}$} & \multirow{2}{*}{$\begin{array}{l}1.97 \\
(0.1607) \\
\end{array}$} \\
\hline & 1 & & \\
\hline \multirow{2}{*}{ SM } & 0 & \multirow{2}{*}{$\begin{array}{l}17.24 * * * \\
(0.0000)\end{array}$} & \multirow{2}{*}{$\begin{array}{l}14.17 * * * \\
(0.0002)\end{array}$} \\
\hline & 1 & & \\
\hline \multirow{2}{*}{$\mathrm{SH}$} & 0 & \multirow{2}{*}{$\begin{array}{l}3.09 * \\
(0.0789)\end{array}$} & \multirow{2}{*}{$\begin{array}{l}2.22 \\
(0.1365)\end{array}$} \\
\hline & 1 & & \\
\hline \multirow{2}{*}{$\mathrm{BL}$} & 0 & \multirow{2}{*}{$\begin{array}{l}0.24 \\
(0.6250) \\
\end{array}$} & \multirow{2}{*}{$\begin{array}{l}0.00 \\
(0.9679) \\
\end{array}$} \\
\hline & 1 & & \\
\hline \multirow{2}{*}{ BM } & 0 & \multirow{2}{*}{$\begin{array}{l}3.71^{*} \\
(0.0541)\end{array}$} & \multirow{2}{*}{$\begin{array}{l}1.24 \\
(0.2662)\end{array}$} \\
\hline & 1 & & \\
\hline \multirow{2}{*}{ BH } & 0 & \multirow{2}{*}{$\begin{array}{l}9.45 * * * \\
(0.0021)\end{array}$} & \multirow{2}{*}{$\begin{array}{l}4.91 * * \\
(0.0268)\end{array}$} \\
\hline & 1 & & \\
\hline \multicolumn{4}{|c|}{ Panel B: Negative Portfolio Momentum } \\
\hline \multirow{2}{*}{ SL } & 0 & \multirow{2}{*}{$\begin{array}{l}1.46 \\
(0.2265)\end{array}$} & \multirow{2}{*}{$\begin{array}{l}0.08 \\
(0.7784)\end{array}$} \\
\hline & 1 & & \\
\hline \multirow{2}{*}{ SM } & 0 & \multirow{2}{*}{$\begin{array}{l}0.19 \\
(0.6654)\end{array}$} & \multirow{2}{*}{$\begin{array}{l}0.02 \\
(0.8909)\end{array}$} \\
\hline & 1 & & \\
\hline \multirow{2}{*}{$\mathrm{SH}$} & 0 & \multirow{2}{*}{$\begin{array}{l}0.84 \\
(0.3592)\end{array}$} & \multirow{2}{*}{$\begin{array}{l}0.84 \\
(0.3600)\end{array}$} \\
\hline & 1 & & \\
\hline \multirow{2}{*}{ BL } & 0 & \multirow{2}{*}{$\begin{array}{l}0.34 \\
(0.5578)\end{array}$} & \multirow{2}{*}{$\begin{array}{l}0.16 \\
(0.6873)\end{array}$} \\
\hline & 1 & & \\
\hline \multirow{2}{*}{ BM } & 0 & \multirow{2}{*}{$\begin{array}{l}3.33^{*} \\
(0.0680)\end{array}$} & $2.98^{*}$ \\
\hline & 1 & & $(0.0843)$ \\
\hline & 0 & 0.16 & 0.01 \\
\hline BH & 1 & $(0.6917)$ & $(0.9043)$ \\
\hline
\end{tabular}

\footnotetext{
${ }^{19}$ For the procedure visit: https://fred.stlouisfed.org/series/GBRRECDM
} 
Given this evidence, one can infer that style momentum strategies whose survival curves are statistically the same across economic cycles are expected to exhibit similar profitability irrespective of the economic regimes. That is, one can trade on either positive or negative momentum utilising its survival time without being concerned about the recession or expansion state of the market. We test this assumption during the trading period January 2001 to June 2014 where there is $51 \%$ of peak and $49 \%$ of trough months in the UK economy. To save space, we present profitability across economic cycles for long winner/short loser style rotation strategy only ${ }^{20}$.

Table 11: Winner/Loser Style Rotation Across Business Cycles

This table reports the annualised Mean Return (in \%), Standard Deviation (in \%), Sharpe Ratio and break-even transaction costs (in basis points, BPS) of winner/loser momentum trading. The switching between portfolios is determined by two criteria: long position in the portfolio with the highest positive momentum and short position in the portfolio lowest negative momentum in month $t$. If the positive (negative) momentum is not observed we invest in the UK 3-month T-Bill. Buy-and-hold is the FTSE All Share index. The economic regimes are the OECD based Recession Indicators for the United Kingdom taken from Federal Reserve Bank of St. Louis.

Panel A: Recession

\begin{tabular}{lllll}
\hline & Mean Return (\%) & Std. Dev (\%) & Sharpe Ratio & Break-even TC \\
\hline $\begin{array}{l}\text { Winner/loser Style Rotation } \\
\text { Long Winner }\end{array}$ & 15.91 & 15.72 & 0.4676 & 404.53 BPS \\
\hline $\begin{array}{l}\text { Winner/loser Style Rotation } \\
\text { Short Loser }\end{array}$ & 23.14 & 14.82 & 0.7708 & 256.50 BPS \\
\hline $\begin{array}{l}\text { Winner/loser Style Rotation } \\
\text { Long-Short }\end{array}$ & 20.23 & 9.58 & 0.9397 & 272.28 BPS \\
\hline Buy-Hold of FTSE All Share & -1.01 & 14.73 & -0.2603 & 212.25 BPS \\
\hline Panel B: Expansion & 24.97 & 16.88 & 0.7225 & 49.12 BPS \\
\hline $\begin{array}{l}\text { Winner/loser Style Rotation } \\
\text { Long Winner }\end{array}$ & 15.64 & 11.22 & 0.5681 & 143.38 BPS \\
\hline $\begin{array}{l}\text { Winner/loser Style Rotation } \\
\text { Short Loser }\end{array}$ & 21.07 & 7.87 & 1.0967 & 0.2970 \\
\hline $\begin{array}{l}\text { Winner/loser Style Rotation } \\
\text { Long-Short Loser }\end{array}$ & 11.49 & 14.38 & & \\
\hline Buy-Hold of FT All Share & & & \\
\hline
\end{tabular}

Earlier in this study, Table 9 has shown that both long and short segment of the winner/loser style rotation strategy separately generates considerably higher Sharpe ratios than the buyand-hold strategy in the overall trading period January 2001 to June 2014. Consistent with what one would expect intuitively, Table 11 shows that in the recessions it pays more to be short, while in expansions the long side of the portfolio has the edge. Nevertheless, in both expansion and recession, the highest Sharpe ratios (well above those of the FTSE All Share

\footnotetext{
${ }^{20}$ Note that the remaining strategies presented in this paper lead to the same qualitative conclusions.
} 
index) are generated by the long winner/short loser strategy. Investors can pay transaction costs up to $2.7 \%$ per trade in recessions (1.4\% in expansions) and still generate better performance than the FTSE All Share benchmark. Hence, regardless of the economic state, our momentum strategies continue to generate strong risk-adjusted performance at a feasible level of transaction costs.

\subsection{Surviving the Financial Crisis}

In this section, we present the results of trading based on our mean momentum survival time methodology in the sub - sample period from November 2007, which Bank of St. Louis database marks as the start of the UK crisis period, to the end of the sample in June 2014. Mean survival times are estimated for the in-sample period January 1980-October 2007. The mean survival time of positive momentum is 4 months across portfolios and the mean negative momentum survival time of SL, SM, SH, BL, BM and $\mathrm{BH}$ portfolios are 3, 2, 3, 3, 2 , and 3 months respectively. The same long-only, short-only and long-short strategies as used previously in this paper are applied. The buy-and-hold strategy, as before, represents the investment in each of the relevant portfolios. 
Table 12: Trading Rules from the beginning of Recession (2007M11 to 2014M06)

The table reports annualised mean return, standard deviation, Sharpe ratio, number of switches and the breakeven transaction costs (TC) for three different trading strategies and the buy-and hold over the trading period 2007M11 to 2014M06. The results are reported for each of the six portfolios separately (SL, SM, SH, BL, $\mathrm{BM}, \mathrm{BH})$. Long positive momentum strategy takes a long position in the portfolio if a positive momentum is observed, otherwise invests in T-Bill. Short negative momentum strategy takes a short position in the portfolio if a negative momentum is observed, otherwise invests in T-Bill. Long Positive-Short negative strategy is the combination of the two. The buy-and-hold strategy represents the investment in each of the six portfolios. No.of switches represent the number of times we switch between the long, the short position and the T-bill. Two switches are equivalent to one round trip transaction. Break-even transaction costs (TC) represent the maximum cost (in basis points, BPS) an investor can pay per switch (trade) and still perform as well as the buy and hold strategy. Trading period: November 2007- June 2014.

\begin{tabular}{|c|c|c|c|c|c|c|}
\hline Portfolio & Trading Strategies & $\begin{array}{l}\text { Mean } \\
\text { Return }\end{array}$ & $\begin{array}{l}\text { Std. } \\
\text { Dev. }\end{array}$ & $\begin{array}{c}\text { Sharpe } \\
\text { Ratio }\end{array}$ & $\begin{array}{c}\text { No. of } \\
\text { Switches }\end{array}$ & $\begin{array}{r}\text { Break Even } \\
\text { TC } \\
\end{array}$ \\
\hline \multirow{4}{*}{$\begin{array}{l}\text { Small Size } \\
\text { \& Low } \\
\text { BTM (SL) }\end{array}$} & Long Positive Mom & 20.18 & 12.45 & 1.45 & 14 & $527.75 \mathrm{BPS}$ \\
\hline & Short Negative Mom & 5.43 & 10.78 & 0.44 & 13 & Negative \\
\hline & Long Pos.-Short Neg. Mom & 13.02 & 7.16 & 1.60 & 27 & $363.65 \mathrm{BPS}$ \\
\hline & Buy and Hold & 9.46 & 17.97 & 0.53 & - & - \\
\hline \multirow{4}{*}{$\begin{array}{l}\text { Small Size } \\
\& \text { Medium } \\
\text { BTM (SM) }\end{array}$} & Long Positive Mom & 20.63 & 12.31 & 1.49 & 14 & $526.15 \mathrm{BPS}$ \\
\hline & Short Negative Mom & 7.46 & 11.01 & 0.61 & 16 & Negative \\
\hline & Long Pos.-Short Neg. Mom & 14.27 & 7.68 & 1.63 & 30 & $363.70 \mathrm{BPS}$ \\
\hline & Buy and Hold & 9.91 & 19.40 & 0.53 & - & - \\
\hline \multirow{4}{*}{$\begin{array}{l}\text { Small Size } \\
\text { \& High } \\
\text { BTM (SH) }\end{array}$} & Long Positive Mom & 20.36 & 16.20 & 1.15 & 12 & 833.92 BPS \\
\hline & Short Negative Mom & 3.60 & 18.44 & 0.23 & 17 & $8.65 \mathrm{BPS}$ \\
\hline & Long Pos.-Short Neg. Mom & 12.92 & 8.63 & 1.33 & 29 & 433.33 BPS \\
\hline & Buy and Hold & 3.52 & 24.17 & 0.22 & - & - \\
\hline \multirow{4}{*}{$\begin{array}{c}\text { Big Size } \\
\text { \& Low } \\
\text { BTM (BL) }\end{array}$} & Long Positive Mom & 12.15 & 8.55 & 1.25 & 10 & 299.40 BPS \\
\hline & Short Negative Mom & 1.44 & 6.80 & 0.08 & 11 & Negative \\
\hline & Long Pos-Short Neg Mom & 6.85 & 5.05 & 1.12 & 21 & Negative \\
\hline & Buy and Hold & 9.53 & 12.47 & 0.70 & - & - \\
\hline \multirow{4}{*}{$\begin{array}{l}\text { Big Size } \\
\text { \& Medium } \\
\text { BTM } \\
\text { (BM) }\end{array}$} & Long Positive Mom & 11.54 & 9.88 & 1.03 & 15 & 335.67 BPS \\
\hline & Short Negative Mom & 8.81 & 8.47 & 0.92 & 10 & $372.64 \mathrm{BPS}$ \\
\hline & Long Pos-Short Neg Mom & 10.43 & 5.74 & 1.56 & 25 & 389.30 BPS \\
\hline & Buy and Hold & 4.35 & 18.32 & 0.26 & - & - \\
\hline \multirow{4}{*}{$\begin{array}{c}\text { Big Size } \\
\text { \& High } \\
\text { BTM }(\mathrm{BH})\end{array}$} & Long Positive Mom & 10.64 & 12.40 & 0.78 & 14 & $329.82 \mathrm{BPS}$ \\
\hline & Short Negative Mom & 1.33 & 12.45 & 0.08 & 15 & Negative \\
\hline & Long Pos-Short Neg Mom & 6.40 & 7.43 & 0.73 & 29 & 169.40 BPS \\
\hline & Buy and Hold & 3.63 & 17.78 & 0.22 & - & - \\
\hline
\end{tabular}

The results in this table are overall consistent with the ones reported for the whole sample period in Tables 6-8. Trading on positive momentum is profitable for transaction costs per trade up to $5.3 \%-8.3 \%$ for various small cap portfolios and up to $3 \%-3.3 \%$ per trade for 
various large cap portfolios. With the exception of BM portfolio trading, the short-only strategy does not pay off. The long-short strategy generates highest Sharpe ratios in most portfolios. Similar as before, the turnover for long-only and short-only strategy is on average $100 \%$ p.a. (around 2 switches per year or 1 round-trip) and on average $200 \%$ p.a. for the long/short strategy. Given the threshold levels of transaction costs per year discussed in section 4.3. and annual turnover levels, all strategies that outperform the buy-and-hold do so at a realistic level of transaction costs.

Table 13 illustrates the winner/loser style rotation strategy in the sub-sample period covering financial crisis from November 2007 to the end of the sample in June 2014. The long-only, short-only and long/short rotation strategies all generate Sharpe ratios at least double those of that of the FTSE All Share buy-and-hold strategy. This is in contrast to Andrikopoulos et al. (2013) who find momentum to be an unprofitable strategy since the start of the financial crisis of $2007 / 08^{21}$. The feasibility of long-only strategy is better than that of short-only and long/short, indicating that as long investors pay less than $2.86 \%$ of transaction costs per trade, they will still generate greater Sharpe ratio than the FTSE All Share buy-and-hold. The breakeven transaction costs figures for short-only and long/short strategy are lower at $0.61 \%$ and $1.67 \%$, making the scope for outperformance narrower and less realistic, given the average UK portfolio trading costs.

Table 13: Winner/Loser Style Rotation after the Recession

The table reports annualised mean return, standard deviation, Sharpe ratio, number of switches and the break-even transaction costs (TC) of winner/loser style rotation momentum trading over the trading period $2007 \mathrm{M} 11$ to 2014M06. The switching between portfolios is determined by two criteria: long position in the portfolio with the highest positive (negative) momentum and short position in the portfolio with the lowest negative momentum in month $t$. If the positive (negative) momentum is not observed we invest in UK three month T-Bill. Buy-and-hold is the FTSE All Share index.

\begin{tabular}{lllll}
\hline & Mean Return (\%) & Std. Dev (\%) & Sharpe Ratio & Break-even TC \\
\hline $\begin{array}{l}\text { Winner/loser Style Rotation } \\
\text { Long }\end{array}$ & 17.00 & 17.28 & 0.93 & 285.49 BPS \\
\hline $\begin{array}{l}\text { Winner/loser Style Rotation } \\
\text { Short }\end{array}$ & 10.22 & 16.56 & 0.60 & 60.69 BPS \\
\hline $\begin{array}{l}\text { Winner/loser Style Rotation } \\
\text { Long-Short }\end{array}$ & 14.97 & 9.64 & 1.39 & 166.43 BPS \\
\hline Buy-Hold of FTSE All Share & 4.34 & 16.09 & 0.27 & - \\
\hline
\end{tabular}

\footnotetext{
${ }^{21}$ The differences in findings may stem from the fact that their study uses daily data to construct momentum returns, they do not exploit momentum survival times but rather rebalance in regular intervals. Their sample ends on $18^{\text {th }}$ February 2010.
} 


\section{$5 \quad$ Conclusions}

This study contributes to the literature of style momentum by studying the survival time of the momentum in the UK style portfolios. Using the Kaplan-Meier method, we estimate momentum survival times for six UK portfolios, equivalents of the US Fama-French size and style portfolios in the period January 1980 - June 2014. Consistent with the findings of Jochum (2000) and Kos \& Todorovic (2008), we report that the positive momentum survives longer than the negative momentum. The estimated mean survival time of positive momentum is 4 months across the six portfolios, whereas the mean survival of negative momentum varies from 2 months for large cap portfolios to 3 months for small cap portfolios.

We apply four simple trading strategies to exploit mean momentum survival times based on these empirical findings: long-only positive momentum in each style portfolio; short-only negative momentum in each style portfolio; long positive/short negative momentum in each style portfolio; and long winner/short loser portfolio - a style rotation strategy based on investing in portfolios with highest positive or lowest negative momentum. With the exception of the short-only negative momentum, all strategies perform better than their buyand-hold benchmarks at a feasible level of transaction costs. This is not surprising as the theoretical survival curves are almost identical to the empirical ones of the negative momentum across our style portfolios, indicating more market efficiency and less scope for profitable trading in short-only strategy. The strongest performance, in terms of incremental Sharpe ratios relative to the buy-and-hold is detected in long winner/short loser strategy, contributing to the evidence that style rotation strategies are profitable in the UK; a finding consistent with Clare, Sapuric and Todorovic (2010). This paper also looks at the differences in survival times and performance of momentum trading strategies across economic regimes. We document that momentum trading based on survival times works well in both recessions and expansions, as well as during recent financial crisis.

Our findings have useful implications for both traders and portfolio managers in that 1) the momentum in style portfolios in the UK is present; 2) the momentum survival time can be successfully exploited in each style portfolio separately (relevant for consistent style investors); 3) the momentum survival time leads to profitable trading in style rotation strategy (relevant for hedge fund managers) and 4) momentum trading based on mean survival times is feasible when accounting for costs. One of the limitations of the study is that the trading strategies are applied on the monthly data frequency (typical of momentum trading) but that 
implies rounding of our mean survival times to say four months, whereas actual survival time estimated may have been 4.3 months. Additionally, the length of momentum survival may be impacted by some macroeconomic conditions and may vary over time. Hence, this study could be extended to look into the (macroeconomic or market) factors that may have an impact on the length of momentum survival time.

\section{References:}

Andrikopoulos, P., Clunie, J. and Siganos, A. (2013) Short-selling Constraints and 'Quantitative' Investment Strategies, The European Journal of Finance, 19(1), pp. 19-35.

Agyei-Ampomah, S. (2007) The Post-Cost Profitability of Momentum Trading Strategies: Further Evidence from the UK, European Financial Management, 13(4), pp.776-802.

Arshanapalli, B. G., Switzer, L. N. and Panju, K. (2007) Equity-Style Timing: A Multi-Style Rotation Model for the Russell Large-Cap and Small-Cap Growth and Value Style Indexes, Journal of Asset Management, 8(1), pp. 9-23.

Asness, C. S., Moskowitz, T. J. and Pedersen, L. H. (2013) Value and Momentum Everywhere, The Journal of Finance, 68(3), pp. 929-985.

Avramov, D. and Cheng, Si, Schreiber, A. and Shemer, K. (2016) Scaling Up Market Anomalies, Journal of Investing, Forthcoming. Available at SSRN: https://ssrn.com/abstract=2709178.

Bernstein, W. (2000), The Intelligent Asset Allocator, McGraw-Hill, New York

Carhart, M. (1997) On Persistence of Mutual Fund Performance, Journal of Finance, 52, pp. $57-82$.

Chan, L. K. C., Jegadeesh, N. and Lakonishok, J. (1996) Momentum Strategies, Journal of Finance, 51(5), pp. 1681-1713.

Chelley-Steeley, P. and Siganos, A. (2004) Momentum Profits and Macroeconomic Factors, Applied Economics Letters, 11(7), pp. 433-436.

Chen, H. (2003) On Characteristics Momentum, Journal of Behavioral Finance, 4(3), pp. $137-156$.

Chen, H.-L. and DeBondt, W. (2004) Style Momentum within the S\&P-500 Index, Journal of 
Empirical Finance, 11(4), pp. 483-507.

Chen, L. H., Jiang, G. J. and Zhu, K. X. (2012) Momentum Strategies for Style and Sector Indexes, Journal of Investment Strategies, 1(3), pp. 67-89.

Chordia, T., Roll, R. and Subrahmanyam, A. (2011) Recent Trends in Trading Activity and Market Quality, Journal of Financial Economics, 101(2), pp. 243-263.

Clare, A., Sapuric, S. and Todorovic, N. (2010) Quantitative or Momentum-Based MultiStyle Rotation? UK Experience, Journal of Asset Management, 10(6), pp. 370-381.

Fama, E. F. (1965) The Behavior of Stock-Market Prices, The Journal of Business, 38(1), pp. 34-105.

Fama, E. F. and French, K. R. (1988) Permanent and Temporary Components of Stock Prices, Journal of Political Economy, 96, pp. 246-273.

Froot, K. and Teo, M. (2004) Equity Style Returns and Institutional Investor Flows, NBER Working Paper Series, No. w10355.

Gregory, A., Tharyan, R. and Christidis, A. (2013) Constructing and Testing Alternative Versions of the Fama-French and Carhart Models in the UK, Journal of Business Finance \& Accounting, 40(1\&2), pp. 172-214.

Grinblatt, M., Titman, S. and Wermers, R. (1995) Momentum Investment Strategies, Portfolio Performance, and Herding: A Study of Mutual Fund Behavior, American Economic Review, 85(5), pp. 1088-1105.

Hon, M. and Tonks, I. (2003) Momentum in the UK Stock Market, Journal of Multinational Financial Management, 13(01), pp. 43-70.

Jegadeesh, N. and Titman, S. (2002) Cross-sectional and Time-series Determinants of Momentum Returns, Review of Financial Studies, 15(1), pp. 143-157.

Jegadeesh, N. and Titman, S. (2001) Profitability of Momentum Strategies: An Evaluation of Alternative Explanations, Journal of Finance, 56(2), pp. 699-720.

Jegadeesh, N. and Titman, S. (1993) Returns to Buying Winners and Selling Losers: Implications for Stock Market Efficiency, Journal of Finance, 48(1), pp. 65-91.

Jochum, C. (2000) Does Market Momentum Survive Longer than it Should?, Financial Markets and Portfolio Management, 14(1), pp. 12-23.

Kao, D. L. and Shumaker, R. D. (1999) Equity Style Timing, Financial Analysts Journal, 
55(1), pp. 37-48.

Kaplan, E. L. and Meier, P. (1958) Nonparametric Estimation from Incomplete Observations, Journal of the American Statistical Association, 53(282), pp. 457-481.

Kiefer, N. M. (1988) Economic Duration Data and Hazard Functions, Journal of Economic Literature, 26(2), pp. 646-679.

Kos, H. and Todorovic, N. (2008) S\&P Global Sector Survivals: Momentum Effects in Sector Indices Underlying iShares, The Quarterly Review of Economics and Finance, 48(3), pp. 520-540.

Lesmond, D., Schill, M., Zhou, C. (2004) The Illusory Nature of Momentum Profits, Journal of Financial Economics, 71(2), pp. 349-380.

Levis, M. and Liodakis, M. (1999) The Profitability of Style Rotation Strategies in the United Kingdom, The Journal of Portfolio Management, 26(1), pp. 73-86.

Levis, M. and Tessaromatis, N. (2004) Style Rotation Strategies: Issues of Implementation, Journal of Portfolio Management, 30(4), pp. 160-169.

Lewellen, J. (2002) Momentum and Autocorrelation in Stock Returns, Review of Financial Studies, 15(2), pp. 533-564.

Liu, W., Strong, N. and Xu, X. (1999) The Profitability of Momentum Investing, Journal of Business Finance \& Accounting, 26(9), pp. 1043-1091.

McLean, R. and Pontiff, J. (2016) Does Academic Research Destroy Stock Return Predictability?, Journal of Finance, 71(1), pp. 5-32.

Pagan, A. (1996) The Econometrics of Financial Markets, Journal of Empirical Finance, 3, pp. 15-103.

Peto R., Pike M. C., Armitage P., Breslow N. E., Cox D. R., Howard S. V., Mantel N., McPherson K., Peto J. and Smith P. G. (1977) Design and Analysis of Randomized Clinical Trials Requiring Prolonged Observation of Each Patient. II. Analysis and Examples., British Journal of Cancer, 35(1), pp. 1-39.

Rouwenhorst, K. G. (1998) International Momentum Strategies, Journal of Finance, 53(1), pp. 267-284.

Royston, P. and Parmar, M. K. (2013) Restricted Mean Survival Time: An Alternative to the 
Hazard Ratio for the Design and Analysis of Randomized Trials with a time-to-event Outcome, BMC Medical Research Methodology, 13(1), Article 152.

Sarwar, G., Mateus, C. and Todorovic, N. (2016) A Tale of Two States: Asymmetries in the UK Small, Value and Momentum Premiums, Applied Economics, DOI:10.1080/00036846.2016.1200184.

Stambaugh, R. F., Yu, J. and Yuan, Y. (2012) The Short of it: Investor Sentiment and Anomalies, Journal of Financial Economics, 104(2), pp. 288-302.

Zhao, L., et. al. (2016) On the Restricted Mean Survival Time Curve in Survival Analysis, Biometrics, 72, pp. 215-221. 


\section{Appendix}

Table A1: Theoretical Survival Function

This table reports the survival function of theoretical survival curves (simulated Random Walk and ARMA $(1,1)$ process) for SM (Panel A), SH (Panel B), BL (Panel C), BM (Panel D) and BH (Panel E) portfolio. Empirical $(\mathrm{KM})$ survival curve $(\mathrm{Sj})$ is reported here for comparison purpose with theoretical survival curves. Simple t-test is performed to investigate whether the theoretical survival functions are identical to the positive or negative empirical survival functions of corresponding ordered failure time. P-value less than the significance level implies that the theoretical survival function is significantly different from their corresponding empirical function. Survival functions/probabilities are reported in decimal points. $* * *, * *$ and $*$ imply the significance at $1 \%, 5 \%$ and $10 \%$ level of significance.

\begin{tabular}{|c|c|c|c|c|c|c|}
\hline \multirow{3}{*}{$\begin{array}{l}\text { Ordered } \\
\text { failure time, } \\
t(j)\end{array}$} & \multirow{2}{*}{\multicolumn{2}{|c|}{ Empirical Survival Function }} & \multicolumn{4}{|c|}{ Theoretical Survival Function } \\
\hline & & & \multicolumn{2}{|c|}{ Random Walk } & \multicolumn{2}{|c|}{ ARMA $(1,1)$} \\
\hline & $\begin{array}{l}\text { Positive } \\
\text { Momentum }\end{array}$ & $\begin{array}{l}\text { Negative } \\
\text { Momentum }\end{array}$ & $\begin{array}{l}\text { Positive } \\
\text { Momentum }\end{array}$ & $\begin{array}{l}\text { Negative } \\
\text { Momentum }\end{array}$ & $\begin{array}{l}\text { Positive } \\
\text { Momentum }\end{array}$ & $\begin{array}{l}\text { Negative } \\
\text { Momentum }\end{array}$ \\
\hline \multicolumn{7}{|c|}{ Panel A: Small Size \& Medium book-to-market (SM) Portfolio } \\
\hline 2 & 0.6882 & 0.3333 & $\begin{array}{l}0.5142 * * * \\
(0.0001)\end{array}$ & $\begin{array}{l}0.4925^{* *} \\
(0.0284)\end{array}$ & $\begin{array}{l}0.5677 * * * \\
(0.0054)\end{array}$ & $\begin{array}{l}0.5577 * * * \\
(0.0018)\end{array}$ \\
\hline 3 & 0.4785 & 0.0877 & $\begin{array}{l}0.2653^{* * * *} \\
(0.0000)\end{array}$ & $\begin{array}{l}0.2542 * * * \\
(0.0003)\end{array}$ & $\begin{array}{l}0.3198^{* * * *} \\
(0.0005)\end{array}$ & $\begin{array}{l}0.3135^{* * *} \\
(0.0000)\end{array}$ \\
\hline 4 & 0.3441 & 0.0175 & $\begin{array}{l}0.1358^{* * *} \\
(0.0000)\end{array}$ & $\begin{array}{l}0.1327 * * * \\
(0.0000)\end{array}$ & $\begin{array}{l}0.1749 * * * \\
(0.0001)\end{array}$ & $\begin{array}{l}0.1772 * * * \\
(0.0000)\end{array}$ \\
\hline 5 & 0.2473 & 0 & $\begin{array}{l}0.0671 * * * \\
(0.0000)\end{array}$ & 0.0645 & $\begin{array}{l}0.0938 * * * \\
(0.0000)\end{array}$ & 0.0957 \\
\hline 6 & 0.172 & & $\begin{array}{l}0.0304^{* * *} \\
(0.0000)\end{array}$ & 0.0287 & $\begin{array}{l}0.049 * * * \\
(0.0001)\end{array}$ & 0.0512 \\
\hline 7 & 0.1183 & & $\begin{array}{l}0.0121 \text { *** } \\
(0.0001)\end{array}$ & 0.0104 & $\begin{array}{l}0.0226^{* * *} \\
(0.0004)\end{array}$ & 0.0235 \\
\hline 8 & 0.0699 & & $\begin{array}{l}0.0035^{* * *} \\
(0.0016)\end{array}$ & 0.0025 & $\begin{array}{l}0.0088^{* * *} \\
(0.0038)\end{array}$ & 0.0075 \\
\hline 9 & 0.0376 & & 0 & 0 & 0 & 0 \\
\hline 10 & 0.0108 & & & & & \\
\hline 11 & 0.0054 & & & & & \\
\hline 12 & 0 & & & & & \\
\hline
\end{tabular}


Table A1 (Continued)

\begin{tabular}{|c|c|c|c|c|c|c|}
\hline \multirow{4}{*}{$\begin{array}{l}\text { Ordered } \\
\text { failure time, } \\
t(j)\end{array}$} & \multirow{2}{*}{\multicolumn{2}{|c|}{ Empirical Survival Function }} & \multicolumn{4}{|c|}{ Theoretical Survival Function } \\
\hline & & & \multicolumn{2}{|c|}{ Random Walk } & \multicolumn{2}{|c|}{$\operatorname{ARMA}(1,1)$} \\
\hline & Positive & Negative & Positive & Negative & Positive & Negative \\
\hline & Momentum & Momentum & Momentum & Momentum & Momentum & Momentum \\
\hline \multicolumn{7}{|c|}{ Panel B: Small Size \& High book-to-market (SH) Portfolio } \\
\hline 2 & 0.6919 & 0.4355 & $\begin{array}{l}0.5032 * * * \\
(0.0000)\end{array}$ & $\begin{array}{l}0.4826 \\
(0.5200)\end{array}$ & $\begin{array}{l}0.5598 * * * \\
(0.0023)\end{array}$ & $\begin{array}{l}0.5616^{*} \\
(0.0808)\end{array}$ \\
\hline 3 & 0.4865 & 0.1774 & $\begin{array}{l}0.2563 * * * \\
(0.0000)\end{array}$ & $\begin{array}{l}0.2357 \\
(0.3075)\end{array}$ & $\begin{array}{l}0.311 * * * \\
(0.0001)\end{array}$ & $\begin{array}{l}0.3087 * * \\
(0.0216)\end{array}$ \\
\hline 4 & 0.3459 & 0.0645 & $\begin{array}{l}0.1294 * * * \\
(0.0000)\end{array}$ & $\begin{array}{l}0.1139 \\
(0.1906)\end{array}$ & $\begin{array}{l}0.1722 * * * \\
(0.0000)\end{array}$ & $\begin{array}{l}0.168 * * * \\
(0.0067)\end{array}$ \\
\hline 5 & 0.2432 & 0.0161 & $\begin{array}{l}0.0676 * * * \\
(0.0000)\end{array}$ & $\begin{array}{l}0.0543 * \\
(0.0647)\end{array}$ & $\begin{array}{l}0.0958 * * * \\
(0.0001)\end{array}$ & $\begin{array}{l}0.0883 * * * \\
(0.0008)\end{array}$ \\
\hline 6 & 0.173 & 0 & $\begin{array}{l}0.032 * * * \\
(0.0000)\end{array}$ & 0.0232 & $\begin{array}{l}0.0543 * * * \\
(0.0003)\end{array}$ & 0.0435 \\
\hline 7 & 0.1243 & & $\begin{array}{l}0.0138 * * * \\
(0.0001)\end{array}$ & 0.0087 & $\begin{array}{l}0.028 * * * \\
(0.0006)\end{array}$ & 0.0204 \\
\hline 8 & 0.0865 & & $\begin{array}{l}0.0047 * * * \\
(0.0005)\end{array}$ & 0.0029 & $\begin{array}{l}0.011 * * * \\
(0.0012)\end{array}$ & 0.0076 \\
\hline 9 & 0.0595 & & 0 & 0 & 0 & 0 \\
\hline 10 & 0.0324 & & & & & \\
\hline 11 & 0.0216 & & & & & \\
\hline 12 & 0.0108 & & & & & \\
\hline 13 & 0.0054 & & & & & \\
\hline 14 & 0 & & & & & \\
\hline \multicolumn{7}{|c|}{ Panel C: Big Size \& Low book-to-market (BL) Portfolio } \\
\hline 2 & 0.6552 & 0.4576 & $\begin{array}{l}0.5056^{* * *} \\
(0.0012)\end{array}$ & $\begin{array}{l}0.4988 \\
(0.5818)\end{array}$ & $\begin{array}{l}0.5146 * * * \\
(0.0022)\end{array}$ & $\begin{array}{l}0.5204 \\
(0.4000)\end{array}$ \\
\hline 3 & 0.4425 & 0.2034 & $\begin{array}{l}0.2544 * * * \\
(0.0001)\end{array}$ & $\begin{array}{l}0.2429 \\
(0.5167)\end{array}$ & $\begin{array}{l}0.262 * * * \\
(0.0001)\end{array}$ & $\begin{array}{l}0.2698 \\
(0.2765)\end{array}$ \\
\hline 4 & 0.3161 & 0.1186 & $\begin{array}{l}0.127 * * * \\
(0.0000)\end{array}$ & $\begin{array}{l}0.1203 \\
(0.9720)\end{array}$ & $\begin{array}{l}0.1329 * * * \\
(0.0000)\end{array}$ & $\begin{array}{l}0.142 \\
(0.6324)\end{array}$ \\
\hline 5 & 0.2184 & 0.0508 & $\begin{array}{l}0.0595 * * * \\
(0.0000)\end{array}$ & $\begin{array}{l}0.0619 \\
(0.7399)\end{array}$ & $\begin{array}{l}0.0647 * * * \\
(0.0000)\end{array}$ & $\begin{array}{l}0.0764 \\
(0.4479)\end{array}$ \\
\hline 6 & 0.1437 & 0.0169 & $\begin{array}{l}0.029 * * * \\
(0.0002)\end{array}$ & $\begin{array}{l}0.0317 \\
(0.4670)\end{array}$ & $\begin{array}{l}0.032 * * * \\
(0.0003)\end{array}$ & $\begin{array}{l}0.0405 \\
(0.2533)\end{array}$ \\
\hline 7 & 0.1092 & 0 & $\begin{array}{l}0.0115 * * * \\
(0.0003)\end{array}$ & 0.0137 & $\begin{array}{l}0.0133 * * * \\
(0.0003)\end{array}$ & 0.0191 \\
\hline 8 & 0.0747 & & $\begin{array}{l}0.0028 * * * \\
(0.0012)\end{array}$ & 0.0047 & $\begin{array}{l}0.0031 * * * \\
(0.0013)\end{array}$ & 0.0071 \\
\hline 9 & 0.046 & & 0 & 0 & 0 & 0.0004 \\
\hline 10 & 0.0287 & & & & & 0 \\
\hline 11 & 0.0115 & & & & & \\
\hline 12 & 0 & & & & & \\
\hline
\end{tabular}


Table A1 (Continued)

\begin{tabular}{|c|c|c|c|c|c|c|}
\hline \multirow{4}{*}{$\begin{array}{l}\text { Ordered } \\
\text { failure time, } \\
t(j)\end{array}$} & \multirow{2}{*}{\multicolumn{2}{|c|}{ Empirical Survival Function }} & \multicolumn{4}{|c|}{ Theoretical Survival Function } \\
\hline & & & \multicolumn{2}{|c|}{ Random Walk } & \multicolumn{2}{|c|}{$\operatorname{ARMA}(1,1)$} \\
\hline & Positive & Negative & Positive & Negative & Positive & Negative \\
\hline & Momentum & Momentum & Momentum & Momentum & Momentum & Momentum \\
\hline \multicolumn{7}{|c|}{ Panel D: Big Size \& Medium book-to-market (BM) Portfolio } \\
\hline 2 & 0.6182 & 0.3478 & $\begin{array}{l}0.5053^{* *} \\
(0.0180)\end{array}$ & $\begin{array}{l}0.4809^{*} \\
(0.0984)\end{array}$ & $\begin{array}{l}0.4759 * * * \\
(0.0030)\end{array}$ & $\begin{array}{l}0.4524 \\
(0.1939)\end{array}$ \\
\hline 3 & 0.3818 & 0.1304 & $\begin{array}{l}0.2569 * * * \\
(0.0072)\end{array}$ & $\begin{array}{l}0.2405^{* *} \\
(0.0601)\end{array}$ & $\begin{array}{l}0.2214 * * * \\
(0.0005)\end{array}$ & $\begin{array}{l}0.205 \\
(0.1986)\end{array}$ \\
\hline 4 & 0.2364 & 0.0435 & $\begin{array}{l}0.1351 * * \\
(0.0111)\end{array}$ & $\begin{array}{l}0.1132 * \\
(0.0574)\end{array}$ & $\begin{array}{l}0.1097 * * * \\
(0.0014)\end{array}$ & $\begin{array}{l}0.0859 \\
(0.2382)\end{array}$ \\
\hline 5 & 0.1333 & 0 & $\begin{array}{l}0.0716^{*} \\
(0.0516)\end{array}$ & 0.0539 & $\begin{array}{l}0.0528 * * * \\
(0.0099)\end{array}$ & 0.0342 \\
\hline 6 & 0.0667 & & $\begin{array}{l}0.0339 \\
(0.1554)\end{array}$ & 0.0229 & $\begin{array}{l}0.0225^{*} \\
(0.0503)\end{array}$ & 0.0107 \\
\hline 7 & 0.0485 & & $\begin{array}{l}0.0148^{*} \\
(0.0808)\end{array}$ & 0.0089 & $\begin{array}{l}0.0094 * * \\
(0.0405)\end{array}$ & 0.0021 \\
\hline 8 & 0.0303 & & $\begin{array}{l}0.0051^{*} \\
(0.0935)\end{array}$ & 0.003 & $\begin{array}{l}0.0033^{*} \\
(0.0728)\end{array}$ & 0.0009 \\
\hline 9 & 0.0182 & & 0 & 0 & 0 & 0 \\
\hline 10 & 0.0061 & & & & & \\
\hline 11 & 0 & & & & & \\
\hline \multicolumn{7}{|c|}{ Panel E: Big Size \& High book-to-market (BH) Portfolio } \\
\hline 2 & 0.6527 & 0.36 & $\begin{array}{l}0.4956 * * * \\
(0.0008) * * *\end{array}$ & $\begin{array}{l}0.4984 * \\
(0.0761)\end{array}$ & $\begin{array}{l}0.4923 * * * \\
(0.0006)\end{array}$ & $\begin{array}{l}0.5041^{*} \\
(0.0641)\end{array}$ \\
\hline 3 & 0.4491 & 0.12 & $\begin{array}{l}0.256 \\
(0.0000)\end{array}$ & $\begin{array}{l}0.2457 * * \\
(0.0217)\end{array}$ & $\begin{array}{l}0.2563 * * * \\
(0.0000)\end{array}$ & $\begin{array}{l}0.2567 * * \\
(0.0124)\end{array}$ \\
\hline 4 & 0.3293 & 0.04 & $\begin{array}{l}0.1266 * * * \\
(0.0000)\end{array}$ & $\begin{array}{l}0.1164 * * \\
(0.0259)\end{array}$ & $\begin{array}{l}0.1263 * * * \\
(0.0000)\end{array}$ & $\begin{array}{l}0.1241 * * \\
(0.0142)\end{array}$ \\
\hline 5 & 0.2395 & 0 & $\begin{array}{l}0.0619 * * * \\
(0.0000)\end{array}$ & 0.0519 & $\begin{array}{l}0.0611 * * * \\
(0.0000)\end{array}$ & 0.056 \\
\hline 6 & 0.1557 & & $\begin{array}{l}0.0277 * * * \\
(0.0001)\end{array}$ & 0.0211 & $\begin{array}{l}0.0269 * * * \\
(0.0001)\end{array}$ & 0.0237 \\
\hline 7 & 0.1018 & & $\begin{array}{l}0.0109 * * * \\
(0.0006)\end{array}$ & 0.0081 & $\begin{array}{l}0.0098 * * * \\
(0.0005)\end{array}$ & 0.0089 \\
\hline 8 & 0.0659 & & $\begin{array}{l}0.0032 * * * \\
(0.0036)\end{array}$ & 0.002 & $\begin{array}{l}0.0024 * * * \\
(0.0032)\end{array}$ & 0.0019 \\
\hline 9 & 0.0419 & & 0 & 0 & 0 & 0 \\
\hline 10 & 0.024 & & & & & \\
\hline 11 & 0.018 & & & & & \\
\hline 12 & 0.012 & & & & & \\
\hline 13 & 0.006 & & & & & \\
\hline 14 & 0 & & & & & \\
\hline
\end{tabular}

